تأثير وسائه التواصله الاجتماعي على الأسرة الطسلمة

\title{
تأثير وسائل التواصل الاجتماعي على الأسرة المسلمة
}

(در اسنة تاصيلية)

\section{The Impact of Social Media on The Muslim Family (Rooting Study)}

\author{
دمنال الياس الخضر*
}

\section{Dr.Manal Elyas El Kheder Mohamed}

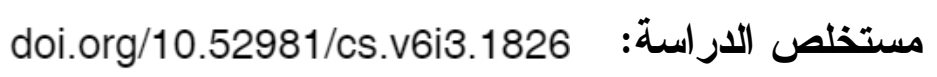

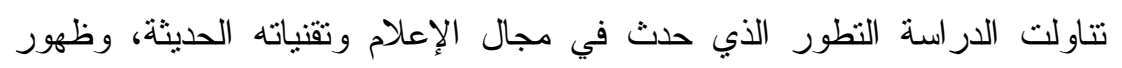

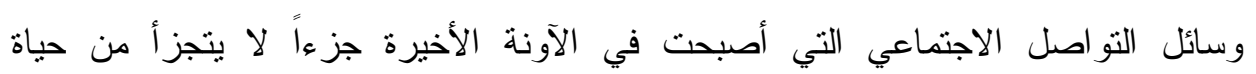

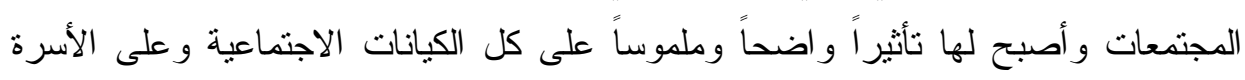

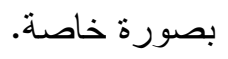

تمثلت مشكلة الدراسة في أن التطور الهائل، وغير المسبوق في تكنولوجيا الاتصال

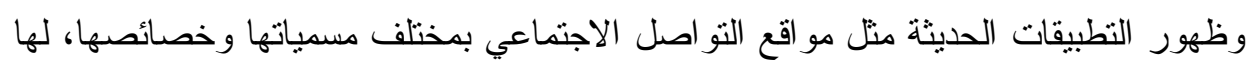

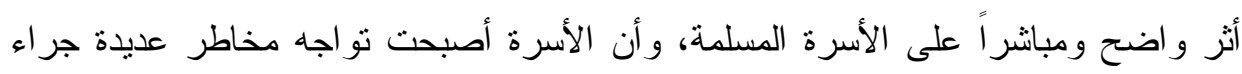
استخدام كل أفر ادها لهذه الوسائل الجاذبة.

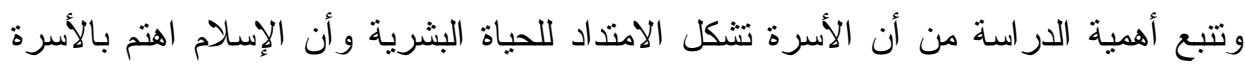

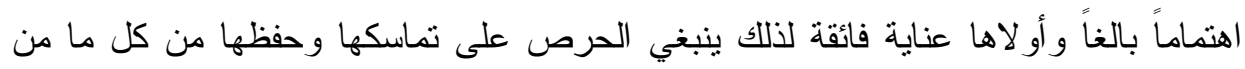
ثأنه أن يغوض دعائمها. هدفت الدراسة إلى التعرف على وسائل النواصل الاجتماعي، والآثار المترنبة على الأسرة

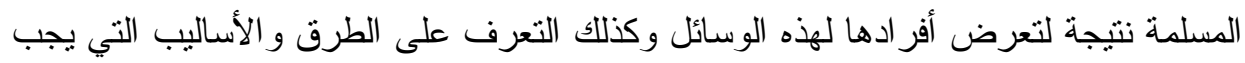

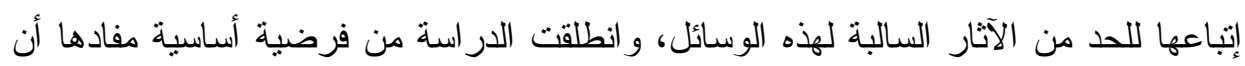

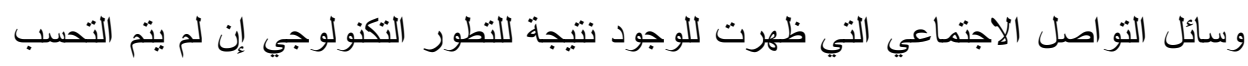
لها و الحد من أثار ها السالبة فأنها ستؤدي إلى تفكلك الأسرة المسلمة و هدم قو اعدها.

* أستاذ مساعد بقسم الصحافة و النشر - كلية الإعلام بجامعة أم درمان الإسلاميةـ السودان.

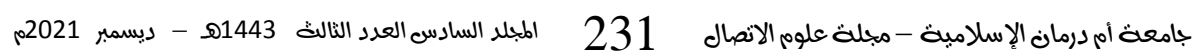




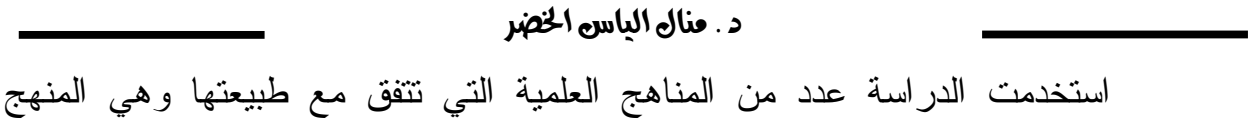

$$
\begin{aligned}
& \text { الوصفي التحليلي لتحليل الظاهرة، و المنهج المقارن لدقارنة النصوص الإسلامية مع القو انين }
\end{aligned}
$$

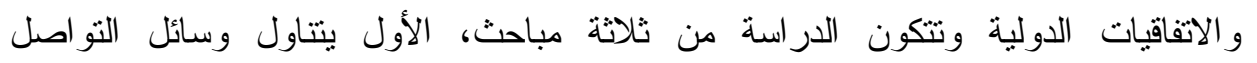

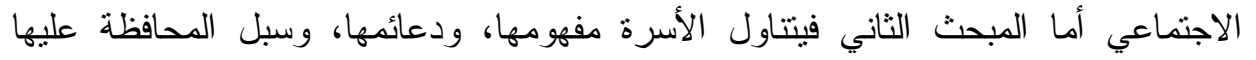

$$
\begin{aligned}
& \text { وثالث يتتاول نأثير وسائل التواصل الاجتماعي على الأسرة المسلمة واثتمل المبحث على ودئل }
\end{aligned}
$$

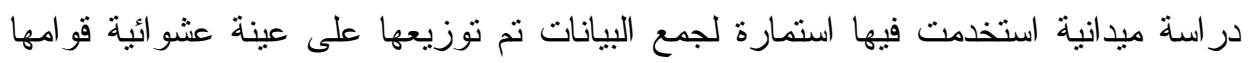

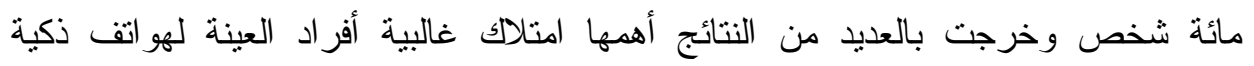

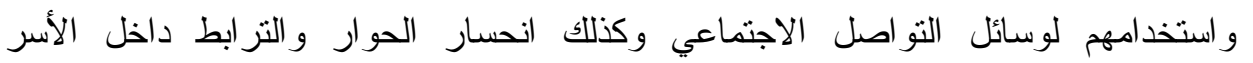

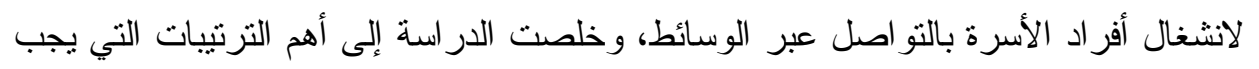

$$
\begin{aligned}
& \text { اتخاذها للحفاظ على الأسرة المسلمة في ظل التحديات التي تو اجهها. }
\end{aligned}
$$

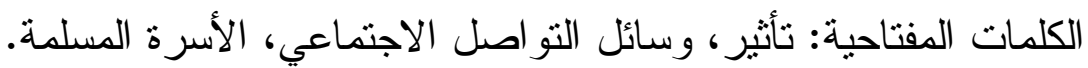

\section{Abstract:}

The study dealt with the development that occurred recently in the field of media and its modern technologies, and the emergence of social communication, and its effect in the last era.

The problem of the study represents the tremendous and unprecedented development in communication projects and the emergence of modern applications such as communication sites with various names and characteristics, which have a clear and direct impact on the Muslim family, and that the family is facing many risks using these attractive products.

the importance of the study is becoming a part of the extension of human life and an interest in that demands attention.

The purpose of the study on this page is to be followed.

The study started from a basic hypothesis that social media has came into existence due to technological development as a result of influencing its negative appearance leads to the disintegration and destruction of the Muslim family.

The study agrees with its nature, which is the descriptive analytical approach to analyze the phenomenon, and the comparative approach deals with the impact of social communication on the Muslim family. Social dialogue, and interdependence within families as a result of the family's affiliation in succession by means, and the study 


\section{تَأثير وسائله التواصله الاجتماعيَ على الأسرة الطسلمة}

concluded this area, which indicates that it defends the environment in which the Muslim family lives in light of the challenges it faces.

Keywords: Impact, Social Media, Muslim Family.

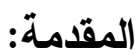

المشهر الحالي للتغيرات التكنولوجية والاجتماعية، و التحويلات المهمة

التي تجري من حيث الكيفية التي نعيش بها ونعمل فيها جعلت من عصرنا الحاضر مجتمعاً للمعرفة تميز بانتشار تكنولوجيا المعلومات و الاتصالات.

فقد انشغل الناس عن الحياة الاجتماعية الو اقعية واتجهو ا نحو التكنولوجيا لأنها أكثر جذباً، وأقل تكلفة وتسهر في خلق علاقات اجتماعية في الفضاء الاككتروني الافتز اضي وهو ما يسمى بالتو اصل الاجتماعي الثبكي الذي قرب المسافات بين الشعوب وأز ال الحدود وز واوج بين الثقافات و أحدث تغييراً كبيراً في كيفية الاتصال و المشاركة بين الناس، وتعد مو اقع التو اصل الاجتماعي عبر الانتزنت من أحدث منتجات تكنولوجيا الاتصال و أكثرها شعبية، وقد استطاعت

على اختلاف أسمائها و أنو اعها أن تغير عاداتتا اليومية وتبدل نمط حياتتا. و أصبح أفر اد الأسرة اليوم في ظل عالم تقني ومجتمع افتر اضي سيطر على اهتمامهم و أخذ الكثير من وقتهم، ولم يعد دور شبكات التو اصل الاجتماعي

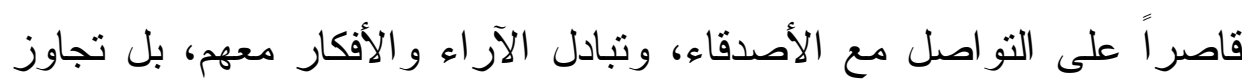
ذلك بكثير حيث أصبحت الثركات الكبرى تستغل هذه المواقع للترويج لمنتجاتها و التو اصل مع جمهور ها، كما أصبحت كثير من الجهات تستثر هذه المو اقع في نشر الأفكار و الترويج للمعتقدات، وبنظرة سريعة وفاحصة نجد أن كل أفر اد الأسرة في العصر الحالي صغيرهم وكبيرهم، دون استثناء يقضون الساعات الطويلة في عزلة تامة عن محيط الأسرة التقليدي منكفئون على شاثات أجهزتهم الصغيرة يتو اصلون مع أصدقاء حقيقيين أو افتر اضبين، وفي ظل هذا الو اقع

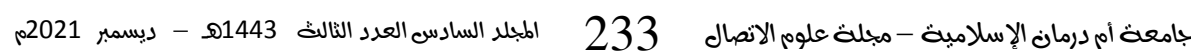


الجديد أصبحت الأسرة خارج نطاق السيطرة و الهيمنة التقليدية للوالدين، حيث

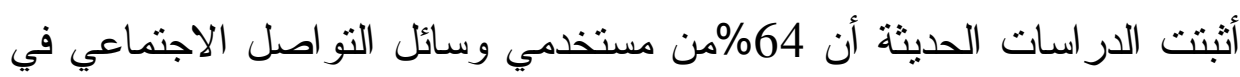

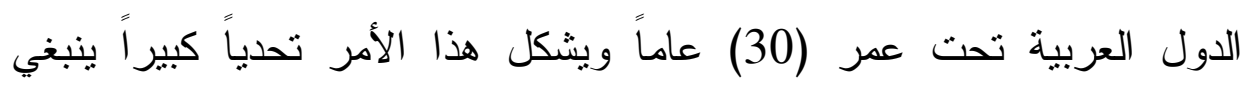
التحسب له بأسر ع ما يكون.

مشكلة الار اسة:

تتطلق مشكلة هذه الدراسة من أن التعرض السهل و الدائم من كل أفر اد

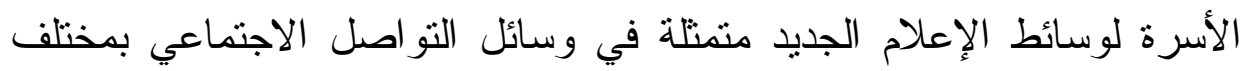

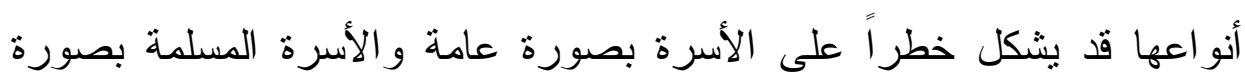

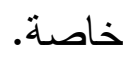
ولما كانت دراسة العلاقة بين الإعلام والأسرة متعددة الجوانب

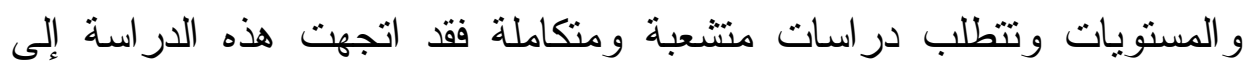

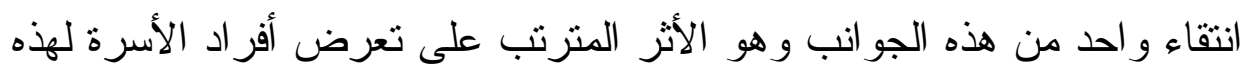
الوسائل دون رقيب أو حسيب. أهمية الدر اسةة: تتطلق أهية الدراسة من أنها تبحث في موضوع يتعلق بالأسرة، والأسرة

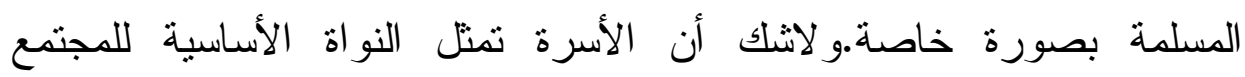

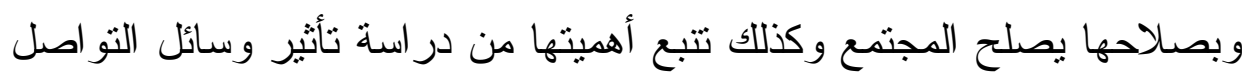
الاجتماعي على الأسرة.

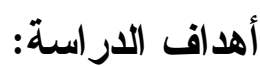

تهدف هذه الدراسة إلى تقصي الآثار المنرتبة على استخدام مواقع التو اصل الاجتماعي و التعرف على مخاطرها، وكذللك تقديم مقترحات للاستفادة

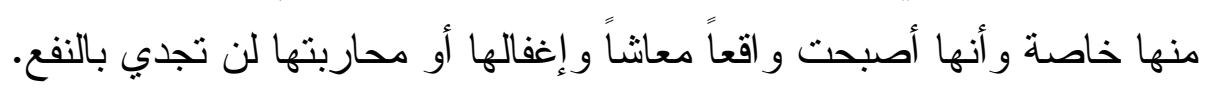




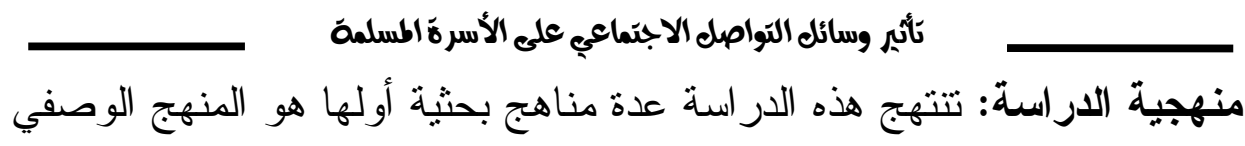
التحليلي القائم على تحليل البيانات و الربط بينها، وكذلك المنهج الوصفي الوثائقي في جمع المعلومات من المصادر و المر اجع المرتبطة بموضوع الدر اسة، وكذلك المنهج الاستقرائي الذي يدرس الواقع الحالي ويتتبأ بالمستقبل وفقاً للمعطيات الحالية. أدوات الاراسة: عمدت الدر اسة إلى استخدام استبانة جمع وتحليل البيانات حيث تم إعداد الاسنبانة نم توزيعها على عينة عشوائية مكونة من (100) مبحوث

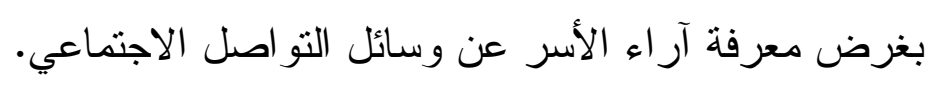
الار اسات السابقة: 1- دراسة عاتكة محمد طه(2016م)(1) بعنوان: اتجاهات الر أي العام النوعي نحو استخدام وسائل التواصل الاجتماعي، حددت مشكلة الدراسة في خطورة مو اقع التو اصل الاجتماعي على المجتمع في حال تركها بدون رقابة، وهدفت الدراسة إلى قياس اتجاهات الرأي العام النوعي نحو استخدام مواقع التو اصل الاجتماعي وتأثير ها على التنشئة الاجتماعية استخدمت الباحثة المنهج الوصفي وخلصت إلى عدد من النتائج أهمها أن هناك عدد مقدر من الجمهور يعتمد على الاجى هذه الوسائل في التواصل مع الآخرين و الحصول على المعلومات ويعتقد أنها مفيدة وذات جدوى. 2- دراسة ماجد بن عبد الله العصيمي(2020)(2بعنوان: التحديات الاجتماعية

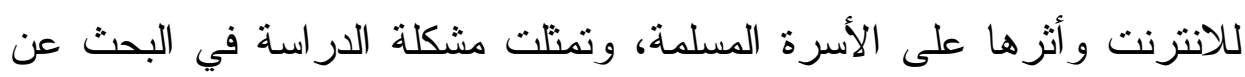
الوصف لأهم التحديات التي تواجه الأسرة المسلمة في ظل الثورة الهائلة التي يشهدها العالم في مجال الاتصالات وخرجت الدر اسة بعدة نتائج أهمها ضرورة وضع مجموعة من الاستر اتيجيات و الأساليب الأسرية لإعادة صياغة الأنشطة

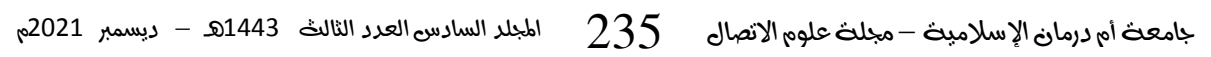




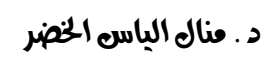

و التفاعلات داخل الأسرة المسلمة بما يخفف من الآثار الاجتماعية للانترنت

$$
\text { ويحد من مخاطر ها. }
$$

ونشير هنا إلى أن الدراستين السابقتين تتفقان مع الدراسة الحالية في أنهم جميعاً يبحثون في إطار التطور الذي حدث نتيجة لتفير ثورة الاتصالات وتأثنر ها على الأسرة و المجتمع وتختلف الدراسة الحالية في أنها تركز فقط على الى الآثار المترتبة على استخدام أفر اد الأسرة لوسائل التو اصل الاجتماعي. وســائل التواصل الاجتماعي: أحدث تطور وسائل الاتصال في نهايات القرن العشرين وبدايات القرن الحادي و العشرين تحولا عالمياً، عمل على تشكيل و اقع جديد لعمليات التو اصل وتفاعل التقافات الإنسانية بفعل قدرته على الانتقال واختراق الحدود و العقول، ودخلت البشرية من بوابة الإعلام الجديد إلى حالة تفاعلية قادتها الثورة المعلوماتية وتطور تكنولوجيا الاتصال . وتسار عت وتيرة انتنار الثبكة العنكبوتية بظهور المواقع الإلكترونية ووسائط التو اصل الاجتماعي منل الفيسبوك، تويتز ، الانستجر ام، الواتساب، و المدونات الاكترونية وغيرها من التطبيقات. محدثة تفاعلاً اجتماعياً وسياسياً في كل الجو انب الحياتية، لاسيما الحياة الأسرية حيث اختصر الزمان و المكان، وقلت بوابات الحراسة الإعلامية و الأسرية، و إجراءات الرقابة و المر اجعة و القانون و أصبح رب الأسرة يقف عاجزاً عن الإحاطة بالمعلومات التي بتلقاها أفر اد ولات أسرته.

مواقع التواصل الاجتماعي (Social Media Sites): هي منظومة من الثبكات الاككترونية التي تسمح للمشترك فيها بإنشاء موقع خاص باه، ومن ثم ربطه من خلا نظام اجتماعي الكتروني مع أعضاء

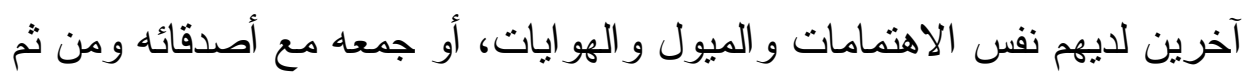


تأئير وسائز التواصله الاجتماعي على الأسرةًا السلمة

إتاحة الفرصة لإنشاء رسائل إلكترونية ونشرها بين أعضاء الموقع و المواقع المشتركة على الثبكات بحريه تامة، وتعرف بأنها شبكة اجتماعية تسمح للأفر اد ببناء جمهور أو شبه جمهور ضمن ملف شخص محدد تتضمن قائمة من المستخدمين يتشاركون الاتصال داخل نظام محدد ويمكن تعريفها أيضاً بأنها مجموعة من التطبيقات الاككترونية التي تهدف للتو اصل و التفاعل لتوطيد العلاقات الاجتماعية فيما بين مستخدميها سواء كان ذللك صوتياً أو مرئياً و الاطلاع و التعامل مع مجريات الأحداث و الإلمام بمختلف القضايا و المو اضيع التي يهتمون بها. نشأة وسائل التواصل الاجتماعي: كانت البدايات الأولى لظهور مصطلح مواقع التواصل الاجتماعي على يد عالم الاجتماع جون بارنز(john A. Barnes) وكانت الولايات المتحدة الأمريكية سابقة العهد في استخدام وسائل التواصل الاجتماعي وكان ذللك عام 1995م من خلال إنشاء موقع (The globe.com) الذي كان عبارة عن تجمع يربط الأفر اد مع بعضهم البعض من خلال غرف الدردشة وتشارك المعلومات، وقد ظهر موقع (Class mute .com) كأول موقع اجتماعي يسمح لمستخدميه التو اصل الاجتماعي مع بعضهم البعض عام (1995) وبلغ عدد مستخدميه

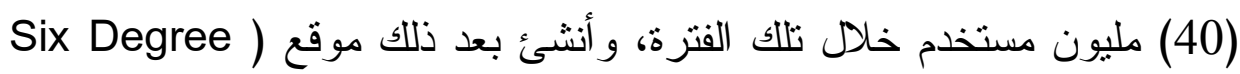
(com عام 1997م وكان الموقع الأول من نوعه الذي يسمح لمستخدميه التو اصل المباثر مع بعضهم من خلال الرسائل و إنشاء ملفات شخصية أو قائمة أصدقاء و هذا ما يميزه عن غيره من المواقع، وبشكل عام كانت جميعاً مواقع تهتم بالتو اصل الاجتماعي بين أفر ادها وبعد ذلك توالت الثبكات الاجتماعية في الظهور حتى عام 2003م أنثئ موقع (My Space .com) و الذي بلغ جامعة أم درمان الإسلامبة - مجلة علوم الانصال 237 المجلد السادسه العدد الثاله 1443هـ - ديسمبر 2021م 


\section{د. منال الباسه الخضر}

مستخدميه في تلك الفترة حو الي 247 مليون مستخدم وظهرت المواقع المختلفة بعد ذلك مثل فرنيد ستر، اليوتيوب، الفيسبوك، وتويتز وظهور موقع الانستجرام لاحقاً (3).

\section{مواقع التواصل الاجتماعي الأكثر انتشاراً:}

الفيسبوك (Facebook):

أطلق موقع الفيسبوك على شبكة الإنترنيت عام 2004م على يد مارك

زوكربيرج (Mark Zuckerbberg) بمساعدة اندرو ماكولوم ( Andrew) (McCollm الطلاب في جامعة هارفارد بالو لايات المتحدة الأمريكية تخصص علم نفس، وكان موقع الفيسبوك أول نشأته عبارة عن موقع داخل الحرم الجامعي ويتكون من (1200) طالب وطالبة من نفس الجامعة، والذي بعدها انتقل لجميع الجامعات، ويعتبر الآن من أكثر المواقع الاجتماعية شعبيةً وانتشار آ، ومهمة فيس بوك هي إعطاء الناس القدرة على المشاركة وجعل العالم أكثر انفتاحاً و اتصالاً ويثارك الناس بالصور و الرو ابط و الفيديو وهو موقع للتعارف فيما بين الناس، يستخدم الفيسبوك الملايين من المستخدمين اليوم، إذ صـار هو وجميع وسائل التو اصل الاجتماعي الثخل الثاغل و الروتيني لكل شخص تقريباً، حيث بمجرد دخول أي شخص المنزل مباشرة يقوم بتشغيل الكمبيوتز و الدخول للفيسبوك أو التويتر، أو مايسبيس، ومن خلال هذه المواقع يقوم بإضافة المئات

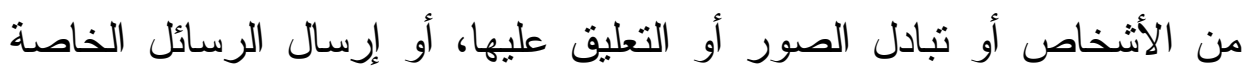
و الحديث، وبلغ عدد مستخدمي الفيسبوك حتى عام 2010م حو الي 500 مليون مستخدم عالمياً ثم وصل العدد في نهاية الربع الثالث من عام 2016مالي 79.1 مليار مستخدم (فعالاً ومتفاعلاً) شهرياً وذلك بارتفاع نسبته 16\% عن عام 2015، أما في الدول العربية فنتير الإحصاءات في بداية عام 2017م إلى 


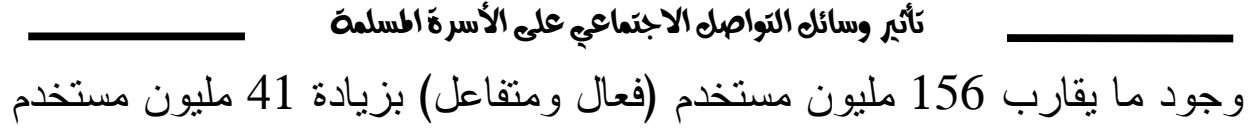
مقارنة بعام 2016 الذي كان فيه إجمالي عدد المستخدمين في الدول العربية

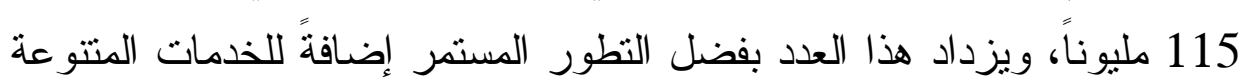
لهذا الموقع (4). تويتر (Twitter):

تم إنشاء هذا الموقع عام 2006 م على يد جالك ودرسي المدير التنفيذي لموقع تويتر في الو لايات المتحدة الأمريكية في سان فر انسيسكو، ولم يكن منذ بدايته موقع اجتماعي فكان مشروع بحثي لثركة (Odeon) بعد ذلك تم إطلاقه كموقع اجتماعي وسمح للمستخدمين باقتنائه وبلغ عدد مستخدميه حتى عام 2010م (50) مليون مستخدم، يتميز هذا الموقع بالرسائل النصية التي تسمى تغريده حتى عام2015م، ويمكن الموقع المستخدمين المسجلين قراعة وكتابة التغريديات، بينما يسمح لغير المسجلين من قر اعتها فقط وحسب الإحصائيات، فقد قدر عدد مستخدمي تويتز حتى عام 2014م(5.797.500) مستخدماً عربياً وبلغ عدد التغريديات في نفس التاريخ (533.165.900) تغريده يومياً حيث تصدرت السعودية استخدام التويتز بـ (204) مليون مستخدم، أما في البحرين فقد بلغ عدد المستخدمين النشطين حوالي (62.200) مستخدم. وبحلول عام 2016 أثنارت الإحصاءات إلى وجود 317 مليون مستخدم حول العالم شهرياً وبلغ عددهم في البلدان العربية 1.11 مليون مستخدم وهو ما يشكل زيادة مقدارها ثناثة أضعاف عن عام 2014م. إجمالياً يقدر عدد حسابات نويتر في مئ البلدان العربية بـ 3.16 مليون حساب في 2017. ونتشر يومياً ما يقارب 4.27 مليون تغريده(5) وتشير أحدث الإحصائيات إلى أن عدد المستخدمين النشطين وصل إلى 330 مليون بحلول عام 2021.

جامعة أم درمان الإسلامبة - مبلة علوم الانصار 239 المبلد السادسه العدد الناله 1443هـ - ديسمبر 2021م 
د. منال الياسه الخضر

انستجرام (Instagram ):

الانستجر ام هو أحد المواقع الاجتماعية الذي يستخدم في التواصل بين

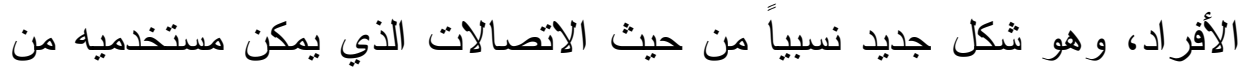

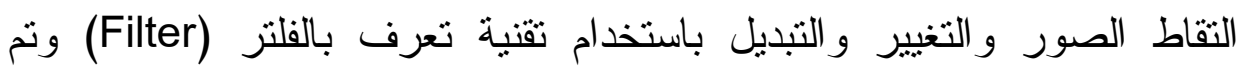

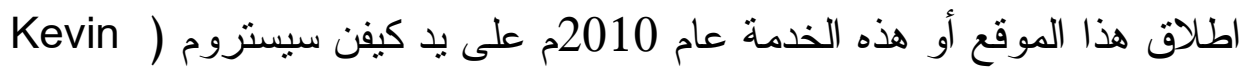
(Systrom الرئيس التتفيذي لموقع الانستجر ام، وهو من المواف اقع الأكثر شعبية

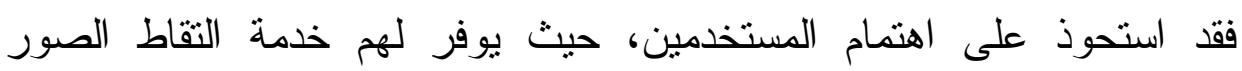

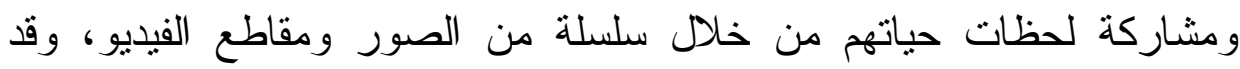

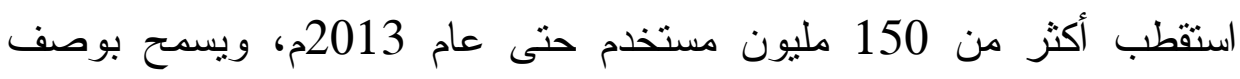

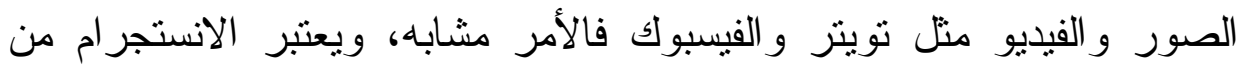
التطبيقات التوعوية الاجتماعية ويستخدم هذا النطبيق (300) مليون مستخدم ولتئر

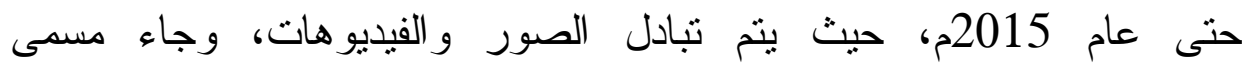
الانستجر ام من كلمة (Instant) المقصود بها لحظة فورية، وكلمة (telegram)

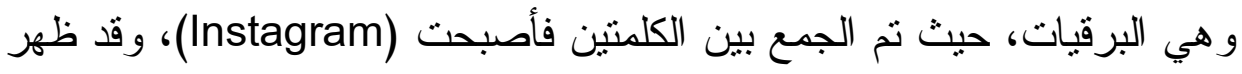
مع ظهور الهو اتق التي تحتوي على الكامير ا وكان إنشاؤه حلاً لثنلاث مشاكل، هي: التقاط الصور بشكل احترافي ومشاركتها على مواقع مختلفة، ثم تحميل

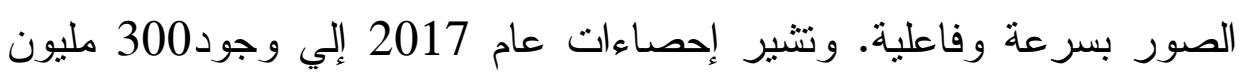

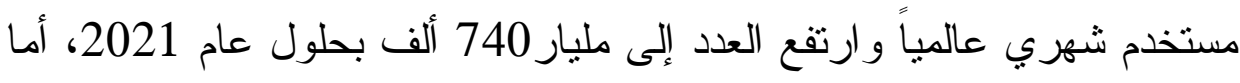
عربياً فقد بلغ عدد مستخدمي انستجرام 1.7 مليون مستخدم وهو ما يشكل

$$
\text { 1.8\% من إجمالي عدد مواطني الدول العربية(6). }
$$

لينكا إن (Linked in):

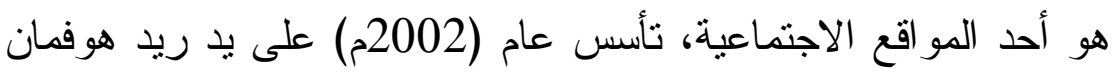

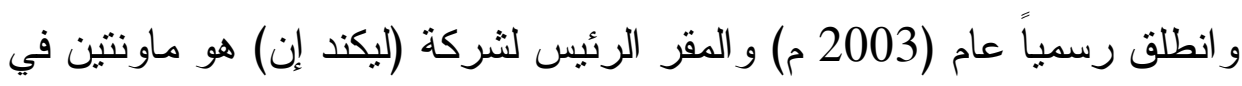




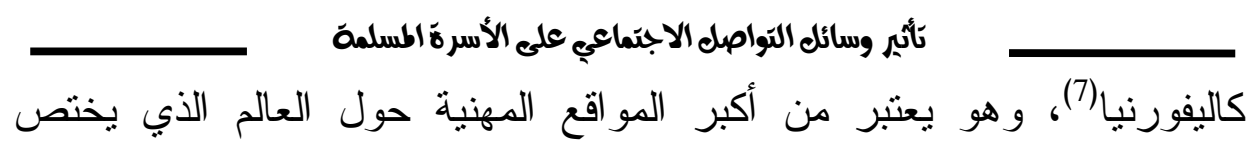
بالتو اصل مع الأثخاص و الوظائف و الأخبار و التحديثات، وبيلغ عدد مستخدميه حتى عام (2015م) حوالي (400) مليون مستخدم، ويلاقي موقع ليكند إن في العالم العربي رواجاً واسعاً في استخدامه، حيث بلغ عدد مستخدميه (4.294.484) مستخدم حتى نهاية يونيو (2012م)، وتتصدر الإمارات الانتشار الأكبر له ومتوسط انتشاره حتى تلك الفترة (2\%) تقريباً، وكانت نسبة استخدامه من قبل الذكور أكثر من الإناث، أما في البحرين فكانت نسبة انتشاره حو الي (7)\% من عدد السكان، وهي نسبة عالية، حيث تأني في المرنبة الثالثة بعد الإمارات. وبلغ إجمالي أعداد مستخدميه في البلدان العربية في العام 2017م حو الي 6.16 مليون مستخدم بزيادة نسبتها 22\%عن عام 2016م. وتتزاوح أعمار 68\%من مستخدمي لينكد إن في البلدان العربية بين18 -35 عام (8). اليوتيوب (YouTube):

اختلفت الآراء حول هذا الموقع باعتباره موقع تواصل اجتماعي، أو موقع لمشاركة مقاطع الفيديو وهو يعتبر موقع الكتروني يوثق المشهد من خلا عرض الحدث و الصور، أطلق هذا الموقع عام (2005 م) على يد نشاد هيرلي وستيف نتين وجاود كريم في مدينة كاليفورنيا حيث يتيح للماليين من الأثخاص المشتركين التو اصل مع بعضهم من مختلف أنحاء العالم، وهو يعتبر وسيط لعرض الإعلانات بمختلف المستويات و الأعمال ويضم أكثز من مليار مستخدم، وبلغٍ عدد مر ات مشاهدة مقاطع الفيديو في العالم العربي (167) مليون مشاهدة يومياً حتى عام 2012م، وهو في المرتبة الثانية عالمياً، وتعتبر السعودية الأعلى بين الدول العربية في نسبة المشاهدة(9).

جامعة أم درمان الإسلامبة - مبلة علوم الاتصال $241 \quad$ المجلد السادسع العدد الثالئ 1443هـ - ديسمبر 2021م 


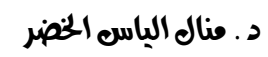

الو اتس أب (WhatsApp)

الوانس أب هو شركة ناثشئة في مجال التكنولوجيا تأسست في أمريكا

وتعتبر برنامج للتواصل الاجتماعي وتعني هذه الكلمة Whats up

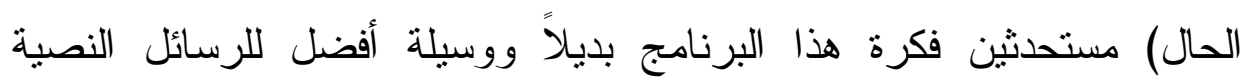

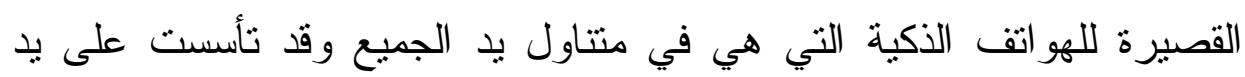

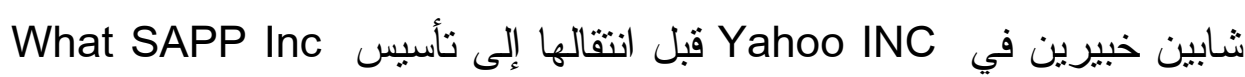

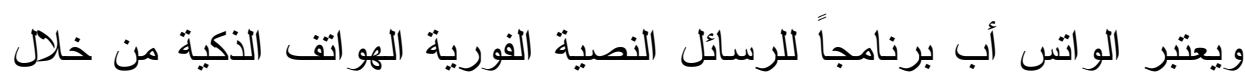

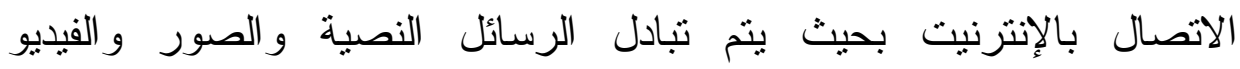
و الروابط، وتأسست هذه الثركة 2009م من قبل بريان أكتون(Brian Acton) وجان كوم (Jan Koum)، حيث كانوا موظفين سابقين في شركة ياهو

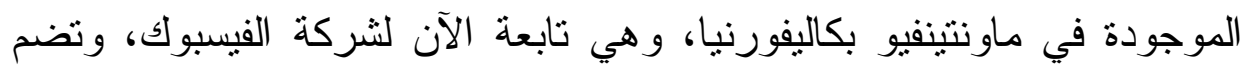

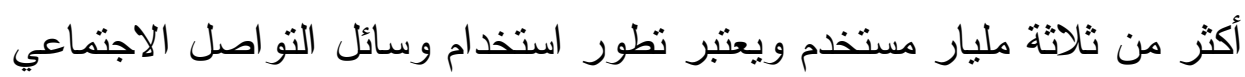

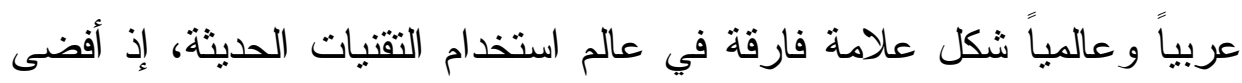

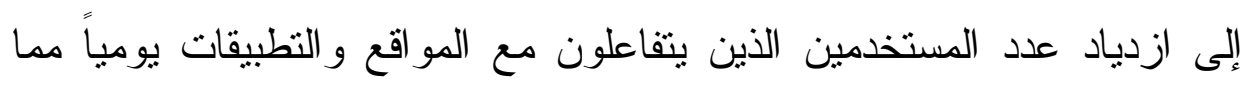

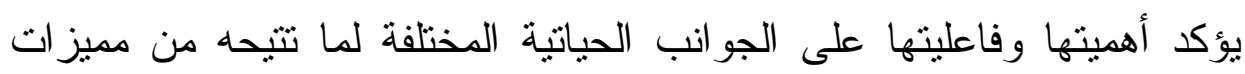
يمكن توظيفها خدمة لأهد افهم وتحقيقاً لتطلعاتهم.

\section{وسائل التواصل الاجتماعي الأقل شهرة:}

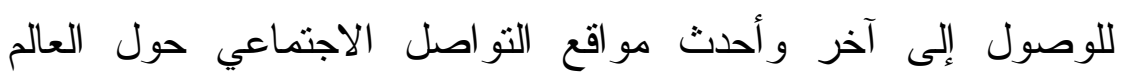

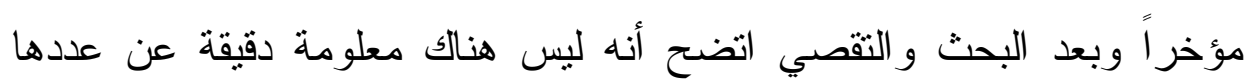

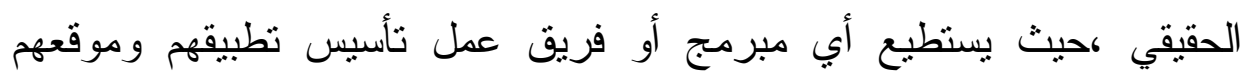
الاجتماعي ونشره، ولكن في كثير من الأحيان لا يستمر الموقع و لا يجد الإقبال

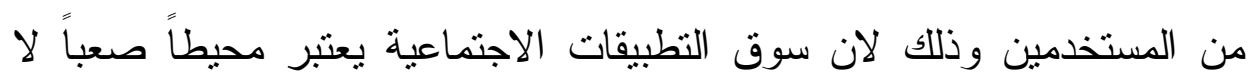

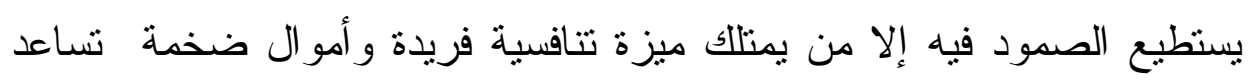


تأئير وسائل التواصله الاجتماعي على الأسرة الطسلمة

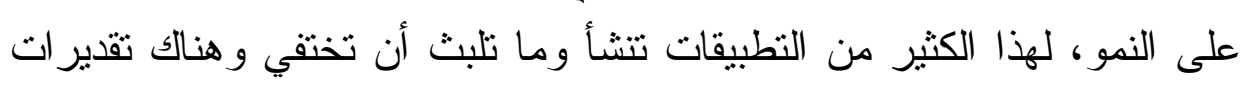
عشوائية تتحدث عن وجود ما بين 800 إلى 5000 موقعاً وتطبيقاً اجتماعياً في عالم اليوم ولكن موقع ويكيبيديا أحصى حوالي 200 موقعاً وتطبيقاً وهنا سنتحدث عن المواقع الأقل شهرة والتي ظهرت إلى السطح ووجدت القبول من المستخدمين بعد أن تتاولنا المواقع الأكثر شهرة مثل الفيسبوك و الو اتساب وأهم

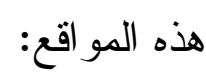

ويتشات (we chat):

وهو ليس مجرد نظبيق للتز اسل الفوري مع أنه للوهلة الأولى يبدو كذلك، حيث يمكن للمستخدمين فيه التراسل و الدردشة ولعب الألعاب و إرسال الأمو ال للأصدقاء ومتابعة الأخبار و الاشتر الك بالمجلات، بالإضافة إلى طلب

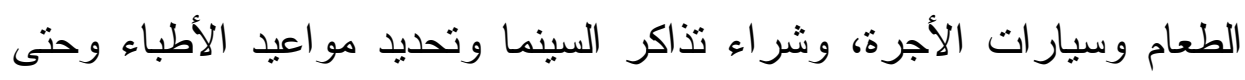
التحقق من المعلومات التي تتعلق بالصحة واللياقة البدنية ويستخدم هذا التطبيق أكثر من مليار مستخدم نشط أغلبهم في الصين. كيوكيو (Q Q

وهو خدمة الرسائل الفورية الأكثر ربحية في الصين و التي تتبه إلى حد كبير اسكايب حيث يوفر للمستخدمين إمكانية الدردشة المرئية والاتصال عبر الانترنت بسهولة، ويمتلك أكثر من 803 مليون مستخدم نشط شهرياً أغلبهم من المر اهقين و الثباب لهذا يعد شبابياً أكثر من ويشات. كيوزون (Q ZONE):

هو أحد أثنهر مواقع التواصل الاجتماعي في الصين تأسس عام 2005م موفراً للمستخدمين خيار ات منل نشر وكتابة اليوميات وإرسال الصور و الاستماع

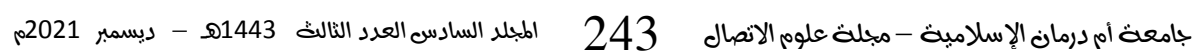


د. منال الباسه الخضر

للموسيقي ومشاهدة الفيديوهات ويمكن عبره نثر البوم صور يحمل أكثر من منالئر 10 ألف صورة.

نمو كيوزون السريع في الصين جعله يعلن في 2009م أنه أصبح من أكبر مواقع التواصل الاجتماعي في العالم بعدد مستخدمين تجاوز 200 مليون فئن مستخدم.

\section{تيكتوك(TIK TOK):}

و هو منصة اجتماعية صينية لاستكثاف و إنشاء ومشاركة مقاطع الفيديو

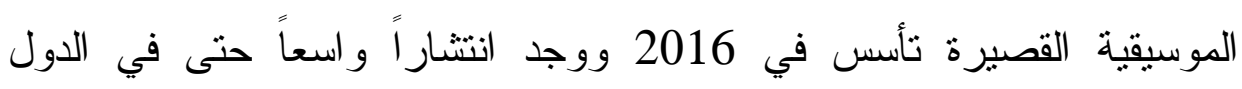
العربية والإفريقية ويعتبر اليوم أكبر منصة لمقاطع الفيديو في العالم بعدد 500 مليون مستخدم نشط شهرياً.

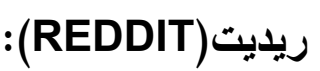

وهو مجتمع مشاركة الأخبار الأكثر شهرة حول العالم حيث يمكن للمستخدمين

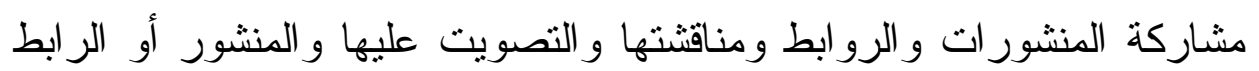

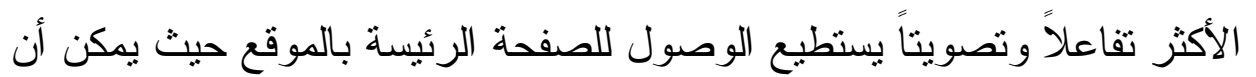

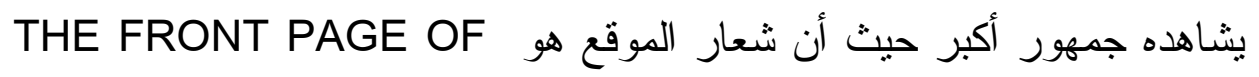
THE INTRNET ويمتلك ريديت أكثر من 330 مليون مستخدم نشط شهرياً أغلبهم من أمريكا الثمالية. (SKYPE) (سكايب): (1) (1)

هو أحد أثنهر خدمات الدردشة الصوتية والمرئية حول العالم تأسس عام

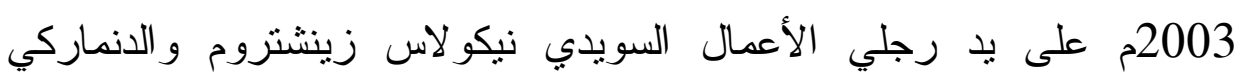

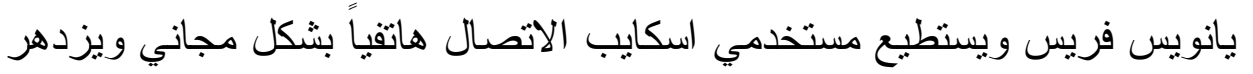




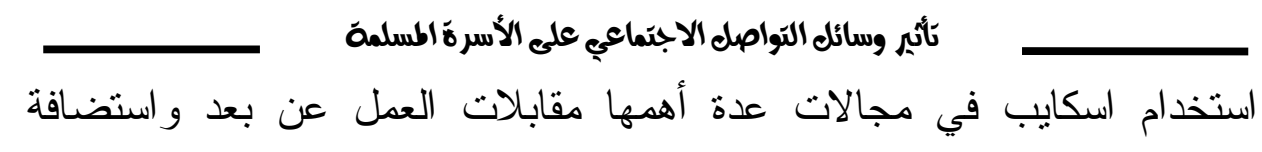
المتحدثين عن بعد في المؤتمر ات الدولية.

وقد استحوذت عليه مايكروسوفت في مايو 2011م بمبلغ 8.5 مليار دولار ودمجته في شبكة خدماتها العريقة ووصل مجموع مستخدميه النشطين شهرياً ما يقرب من 300 مليون مستخدم حول العالم. سنابشات (SNAP CHAT): وهو تطبيق تو اصل اجتماعي لمشاركة اللحظات و الفيديوهات السريعة مع الأصدقاء و المتابعين عبر ميزته الفريدة التي لاقت إعجاب المستخدمين وخاصة المر اهفين وهي مشاركة الصور ولقطات الفيديو الصغيرة التي لا تتجاوز الــــئ 10 ثوان لمدة معينه قبل أن تصبح مختفية إلى الأبد ـ ونمو سنا بشات السريع منذ تأسيسه في 2011م جلب له محاو لات كبرى للاستحو اذ من أثنهر ها محاولة فيسبوك وجوجل وللتطبيق أكثر من 291 مليون مستخدم نشط حول العالم. تلجر ام (TELEGRAM): التلجر ام هو و احد من أهم تطبيقات التر اسل الفوري و أكثر ها أماناً تأسس في 2013م على بد الأخوين الروسبين نيكو لاي وباقلدروف ومن أهم الأثياء التي تجعل تلجرام مختلفاً عن تصنيفات التراسل الأخرى هي خصائص الأمان و التتفير التي بحتويها والتي تمكن المستخدمين من إرسال أي نوع من أنواع الملفات وبأي امتداد دون الخثية من إمكانية التلصص من طرف ثالث بما فيها التطبيق نفسه، ومنذ أن أضاف التطبيق ميزة القنوات إلى خصائصه المذهلة انتقل من كونه تطبيق للتز اسل إلى كونه منصة للتواصل الاجتماعي منكاملة وخاصة أنه يتوفر رسمياً على كل أنظمة النشغيل الخاصة بالهواتف المحمولة و الحو اسيب يستخدمه أكثز من 200 مليون مستخدم نشط شهرياً.

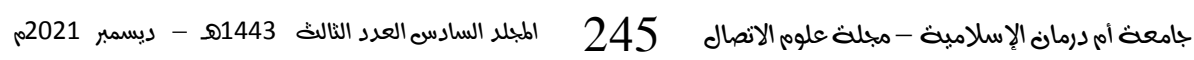




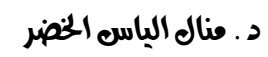

خصائص مواقع التواصل الاجتماعي:

تشترك المواقع الاجتماعية في خصائص أساسية أبرزها الملفات

الثخصية أو الصفحات الثخصية (Profile page) ومن خلالها يمكن التعرف على اسم الثخص ومعرفة المعلومات الأساسية عنه كالنوع، وتاريخ الميلاد، و الاهتمامات والصور الثخصية، بالإضافة إلى غيرها من المعلومات، ويعد الملف الثخصي بو ابة الدخول لعالم الثخص، فمن خلال الصفحة الرئيسة للملف الثخصي يمكن مشاهدة نشاط الثخص مؤخراً، ومعرفة من هم أصدقاؤه؟ وما هي الصور الجديدة التي وضعها؟ إلى غير ذلك من النشاطات وتقدم معظم وسائل الإعلام عبر مواقع التو اصل الاجتماعي خدمات مفتوحة (openness)

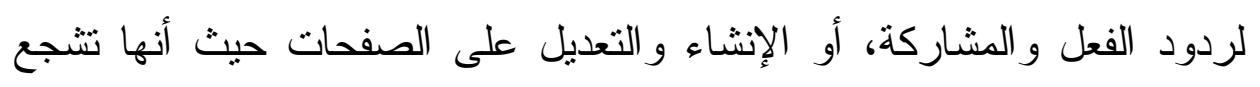
التصويت و التعليقات وتبادل المعلومات بل نادراً ما نوجد أية حواجز أمام الوصول والاستفادة من المحتوى خاصية المحادثة (CONVERSATION) التي تميزها عن الوسائل التقليدية من خلال إتاحتها المحادثة في اتجاهين أي المشاركة والتفاعل مع الحدث أو الخبر أو المعلومة المعروضة، و الأصدقاء و العلاقات ( FRIEND, CONVERSATION) هم بمثابة الأشخاص الذين يتعرف عليهم الشخص لغرض معين، حيث تطلق المواقع الاجتماعية مسمى صديق على الثخص المضاف لقائمة الأصدقاء بينما تطلق بعض المواقع الاجتماعية الخاصة بالمحترفين مسمى اتصال أو علاقة CONTACT على الثخص المضاف للقائمة، وتشجع مواقع التواصل الاجتماعية المشاركة (PARTICIPATION) حيث أنها تطمس الخط الفاصل بين وسائل الإعلام و الجمهور، وتتيح إمكانية إرسال رسائل مباشرة للشخص سو اء كان قائمة الأصدقاء أم لم يكن و إنشاء عدد لمد ولئ لانهائي من الألبومات ورفع مئات الصور عليها، وإتاحة مشاركة هذه الصور 
مع الأصدقاء للاضطلاع و التعليق عليها، ونسئه التواصله الاجتماعي على الأسرة الطسلمة هذه المو اقع للمجتمعات المحلية تشكيل مواقع خاصة بسرعة والتو اصل بشكل فعال، ومن ثم تزتبط تللك

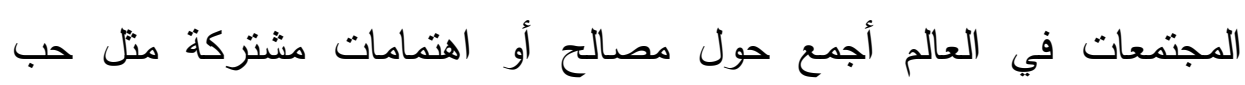
التصوير الفوتوغر افي. أو قضية سياسية أو برنامج تلفزيوني مفضل، ويصبح العالم بالفعل قرية صغيرة تحوي مجتمعاً إلكترونياً منقارباً، ونتيح الكثير من المو اقع الاجتماعية خاصية إنشاء المجموعات (groups) حيث يمكن إنثاء مجموعة بمسمى معين وأهداف محددة، ويوفر الموقع الاجتماعي لمدير المجموعة و المنضمين إليها ساحة أثبه ما تكون بمنتدى حوار مصغر و ألبوم (10).

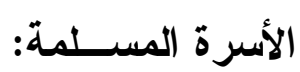
مفهوم الأسرة في اللغة: أ/ قال ابن منظور (أسرة الرجل عشيرته ورهطه الأدنون لأنه يتقوى بهر و الأسرة عثيرة الرجل و أهل بيته)(11). ولفظ الأسرة مشتق من الأسر وهو القيد أو الثذد بالإسار أي أنه يتضمن معنى الإحكام و القوة . ب/ مفهوم الأسرة في الإسلام: لفظ الأسرة في القرآن بمعنى الأهل كما قال تعالى (فلما قضى موسى الأجل

$$
\begin{aligned}
& \text { وسار بأهله)(12) ، وتتقسم الأسرة إلى قسمين:- } \\
& \text { 1/ أصول: وتشمل الآباء و الأمهات وفروع الأبرهاء ولأبناء. } \\
& \text { /2 فروع: وتشمل فروع الأبوين وفروع الأجداد و الجدات. }
\end{aligned}
$$

وتعتبر الأسرة في الدين الإسلامي من أهم ركائز ودعائم المجتمع لأنها تمنل اللبنة الأولى التي تتشأ فيها الأجيال.

جامعة أم درمان الإسلامبة - مجلة علوم الانصال 247 المجلد السادسه العدد الثاله 1443هـ - ديسمبر 2021م 


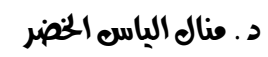

والتعريف الأرجح للأسرة: هي مؤسسة فطرية اجتماعية بين رجل وامرأة،

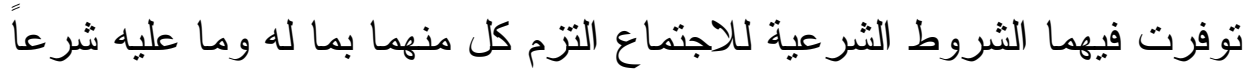
أو شرطاً أو قانوناً (13).

مفهوم الأسرة في المواثيق الدولية:

جاء تعريف الأسرة في المواثيق الدولية منطلقاً من اتجاهات مختلفة وهي الأية كالآتي: الاتجاه الأول: حدد مفهوم الأسرة ارتباطاً بموقعها في المجتمع باعتبار ها تشكل الخلية الأساسية ولها حق التتتع بحمايته ومساعدته.

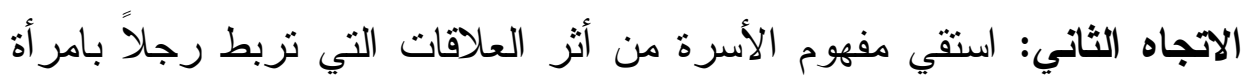
توفرت فيهما شروط الاجنماع. الاتجاه الثالث: حدد مفهوم الأسرة انطلاقاً من علاقتها بعنصر بشري محدد سو اء الطفل أو المر أة وذلك من خلال ديباجة اتفاقية حقوق الطفل. الطن الطاه

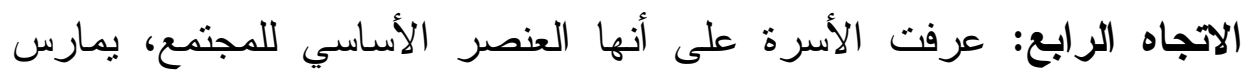

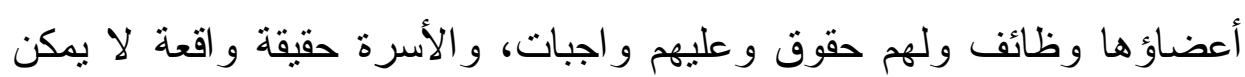
الاستغناء عنها وهي تطلع بمسؤولية النربية و التكوين و التثقيف.

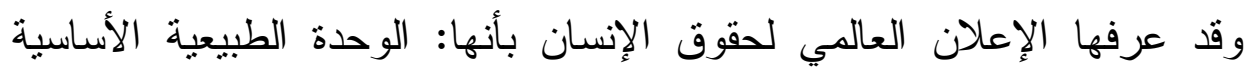

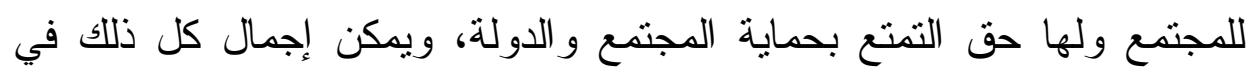

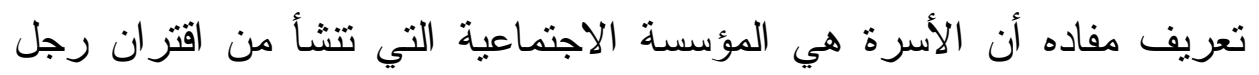

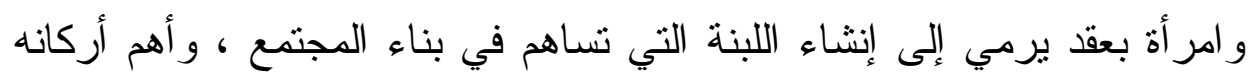

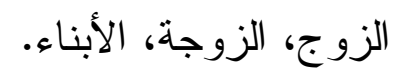

لماذا اهتم الإسلام بالأسرة؟ الزبن أولاً: لأن الأسرة التبي مطالب الفطرة البشرية بالآتي:

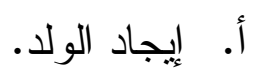




$$
\begin{aligned}
& \text { تأثير وسائل التواصله الاجتماعي على الأسرة اطسلمة } \\
& \text { ب. تدريب الإنسان على المسؤولية. } \\
& \text { ج. تحقيق سنة الزواج. } \\
& \text { د. إثباع مطالب الجسد و الروح. } \\
& \text { ثانياً: لأن للأسرة مهام اجتماعية مثل: } \\
& \text { أ. حفظ النسب من الاختلاط. }
\end{aligned}
$$

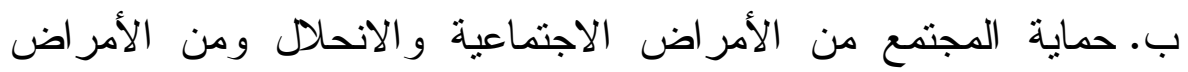

الجنسية المصاحبة للزنا.

ج. إعداد الفرد ليكون إنساناً صالحاً وليقوم بو اجبه التكافلي الاجتماعي. لإنيا.

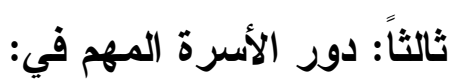

أ. التربية على الأخلاق الفاضلة للفرد و الهجتمع كخلق التضحية والإيثار

$$
\text { و الصبر و التحمل. }
$$

$$
\begin{aligned}
& \text { ب. التزبية السليمة في المر احل الأولى للطفولة. } \\
& \text { ج. كونها الدكان الصحي الوحيد للحضانة. } \\
& \text { واقع الأسرة المسلمة: }
\end{aligned}
$$

هناك عبارة وردت في التقرير الصادر من هيئة الأمم المتحدة عام

1975م بمناسبة العام العالمي للمرأة، نقول تلك العبارة (إن الأسرة بمعناها

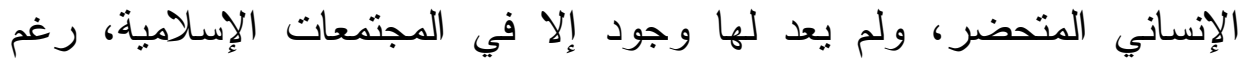

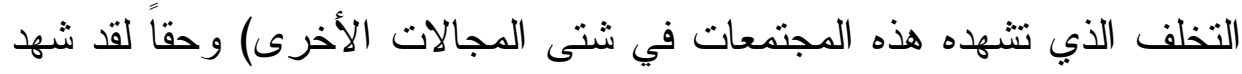

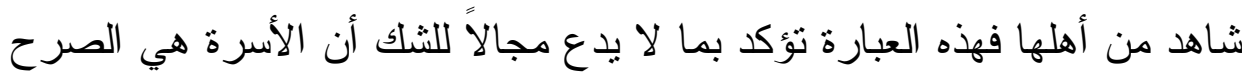
الأخير و الحصن الحصين الباقي للمسلمين في عصر تهاوت فيه كافة الحصون الهان

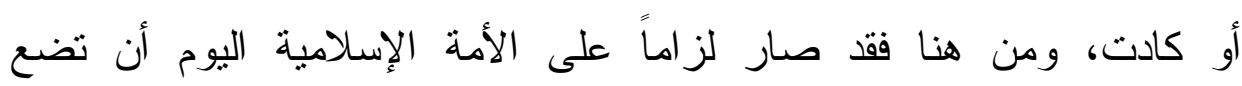

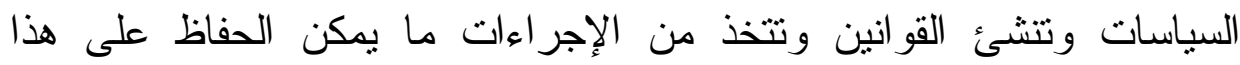

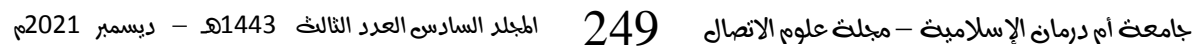




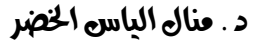

الحصن إذا أر ادت أن تحمي نفسها من الزوال و الفناء بل و الانطلاق إلى آفاق أوسع، صحيح أن الأمة الإسلامية قد تأخذها سنة من النوم في بعض الزّو الأحيان

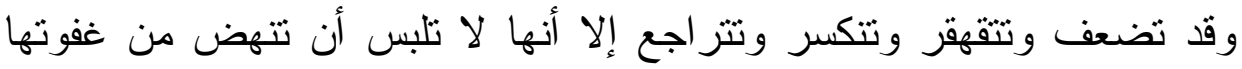

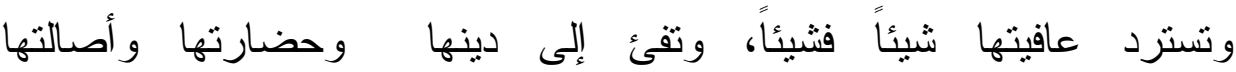
سالمة،ومجتمعاتتا الإسلامية اليوم وفي ظل العولمة بأتنكالها المختلفة والعولمة الإعلامية بصورة خاصة تتعرض لهجوم كاسح يستهذف أول هذه اللبنات وهي الأسرة المسلمة، وقد ظهرت العديد من الآثار السلبية والخطيرة للعولمة سواء على الأسرة المسلمة أو على النظام الاجتماعي في المجتمعات المسلمة عموماً ومن هذه الآثار تمزق الكثير من الأنسجة الاجتماعية، وتردي علاقة الآباء

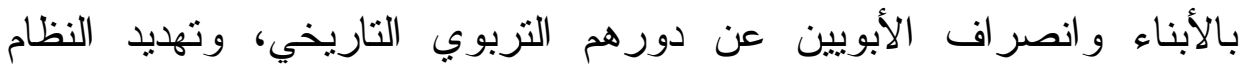
الأخلاقي الإسلامي، فمن خلال العولمة وعبر وسائل الإعلام المختلفة يتم التزرويج وفرض المصطلحات الجديدة متل (Gender) وغير ها.

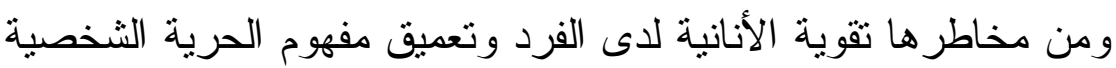

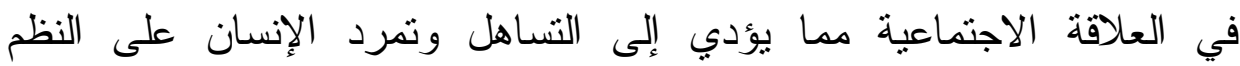

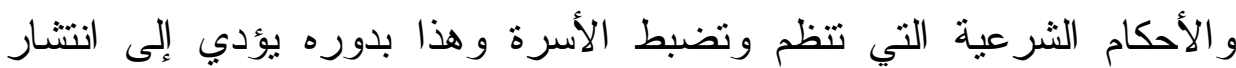
الإباحية، و الرذائل و التحلل الخلقي، و العمل على تفكيك الأسرة و إضعافها وقطع

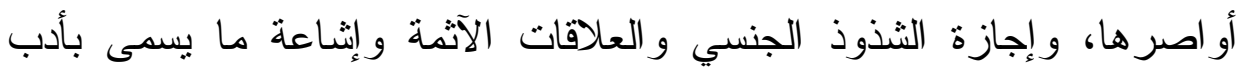

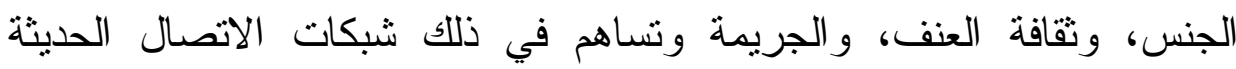

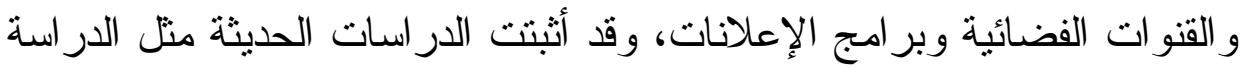
التي وردت في الدراسات السابقة بعنوان التحديات الاجتماعية للانترنت و أثنرها

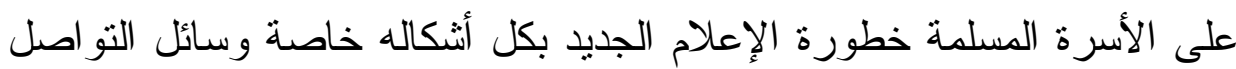

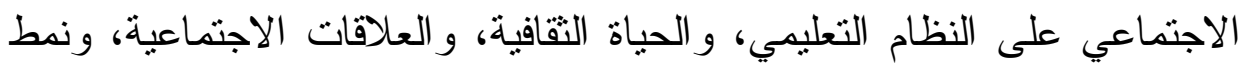




\section{تَأثير وسائله التواصله الاجتماعيَ على الأسرة الطسلمة}

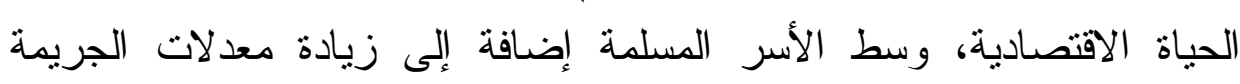

$$
\text { دور الأسرة معدلات الفقر و البطالة. }
$$

وبما أن الأسرة هي اللبنة الأولى في صناعة وتكوين شخصية الفرد و المحافظة على سلامة فطرته وأخلاقياته وسلوكياته وقد اعتتت الثريعة الإسلامية بالأسرة عناية فائقة لما لها من ادوار سامية ومهمة في بناء الإنسان و لأنها الركيزة الأساسية في تحصينهم من الانحر افات سواء الفكرية أو الأخلاقية أو السلوكية لذا يبدأ الإعداد لهذه المهمة منذ اختيار الثريك المناسب ومن ثمة إتباع ما أوصى به الثرع في مرحلة تأسيس الأسرة الصغيرة ثم تأني مرحلة إنجاب الأطفال والذين تقع مسؤوليتهم بالكامل على الأسرة ابتداء من اختيار الاسم المناسب للمولود ثم الاهتمام بمأكله ومشربه وتوفير المسكن المناسب الآمن لله وبعد ذلك تأتي المرحلة الأهم وهي تغذيته الروحية و العقلية بالقيم و المبادئ و الأفكار التي تؤهله ليكون فرداً نافعاً مفيداً لنفسه و لأسرته ولمجتمعهد ذلك أن استقامة الفرد في عقيدته وفكره وثقافته تحدد سلوكه السوي.

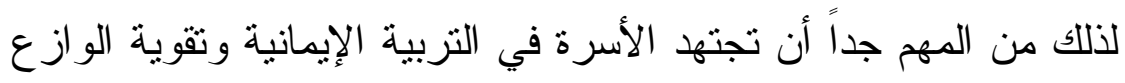
الديني في نفوس الأولاد وغرس الفضيلة و القيم النبيلة لأنها تشكل حصانه من

$$
\text { الانحر افات في الفكر و السلوك. }
$$

ومن الأحاديث المشهورة في هذا المقام حديث عبد الله بن عباس رضي

الله عنهما أنه قال: كنت خلف رسول الله صلي الله عليه وسلم يوما فقال (يال غلام، إني أعلمك كلمات، أحفظ الله بحفظلك، أحفظ الله تجده تجاهك) فأننا نجد أن الرسول صلي الله عليه وسلم اعتتي بابن عباس وهو غلام صغير ورباه على خثية الله ومر اقبته. وهذا ما يجب أن تقوم به كل أسرة وليس هذا فحسب بل بل

جامعة أم درمان الإسلامية - مبلة علوم الاتصال 2512 المجلد السادسم العدد الثاله 


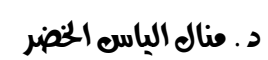

الأسرة مسئولة عن التربية العاطفية و النفسية السوية وذلك بالرحمة بالأولاد

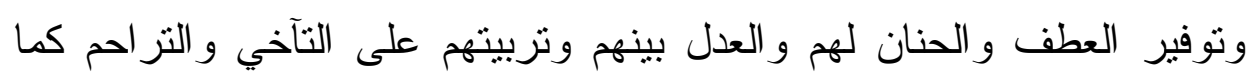

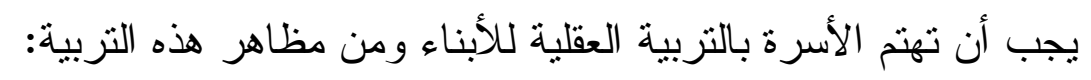
* تعويد عقول الأبناء على النظر و التفكير و عدم التبعية العمياء للآخرين.

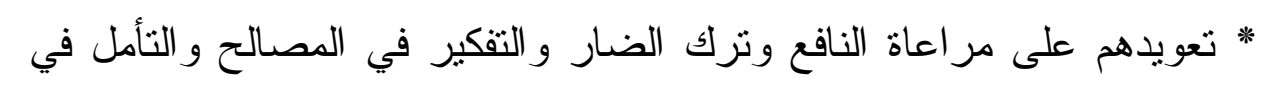
العو اقب.

* تربية الأبناء على ضبط النفس و التروي و الصبر وعدم الاستعجال. "تنظيم أوقاتهم وملؤها بالبر امج العلمية و الترفيهية النافعة. "حسن التحاور معهم بالأسلوب الأمتل لعلاج أب فكر سلبي يطر أ عليهم. * حضهم على مصاحبة ومجالسة العلماء.

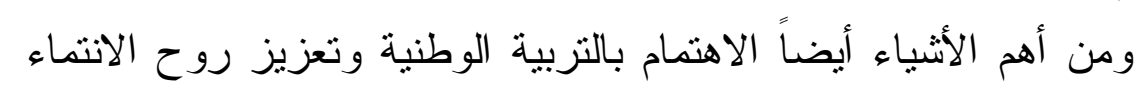

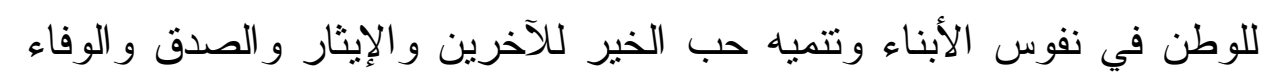

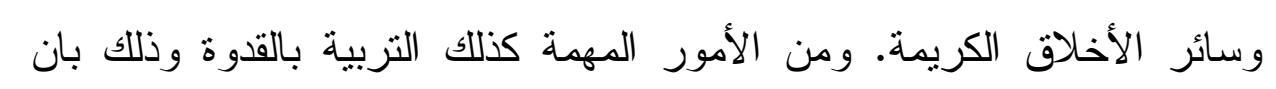

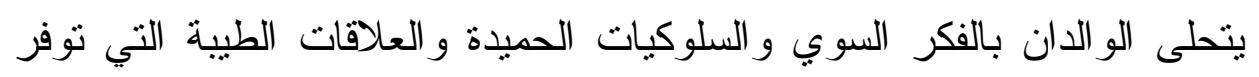

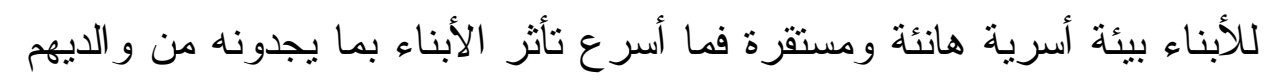

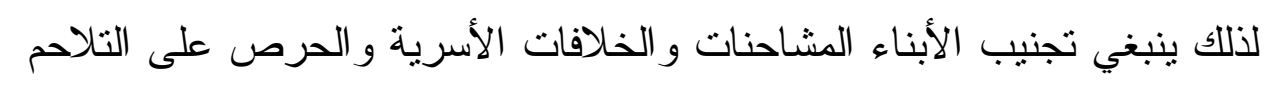
الأسري.

وما يلينا هنا ضرورة الاهتمام بالتربية الوقائية والتي يمكن أن نجملها

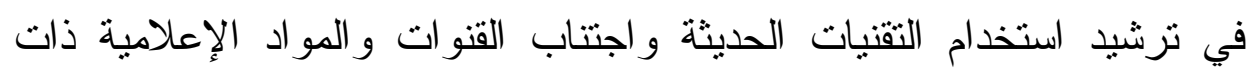

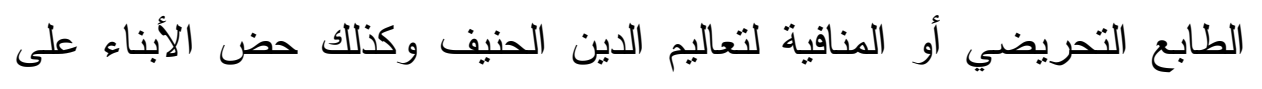

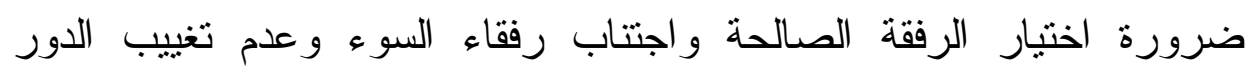

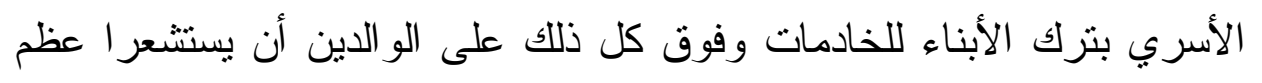

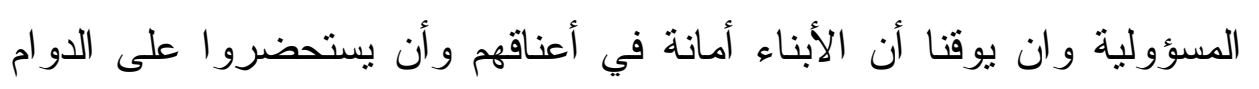

جامعة أم درمان الإسلامية - مبلة علوم الانصال 252 المبلد السادسه العدد النالغ 1443هـ - ديسمبر 2021م 


\section{تأثير وسائه التواصله الاجتماعي على الأسرة اطسلمة}

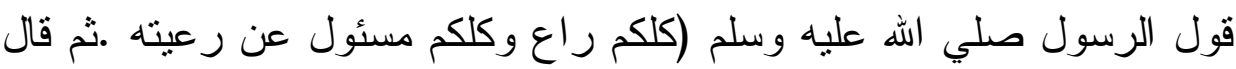

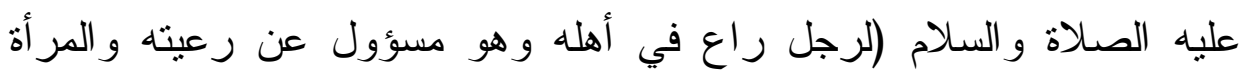
راعية في بيت زوجها ومسئولة عن رعيتها). تأثير وسائل التواصل الاجتماعي على الأسرة المسلمة:

لعقود طويلة ظلت الأسرة و المدرسة والمسجد الأبرة تلعب دوراً أساسياً في تكوين الإنسان وثقافته ، وتساهم في تتكيل منظومة القيم التي يتمسك بها ويتخذها معالم تتحدد من خلالها مقومات السلوك الاجتماعي بما فيها علاقات الآباء بالأبناء

أما اليوم فقد انتقل هذا الدور إلى شبكات الإنترنيت والهو اتف النقالة

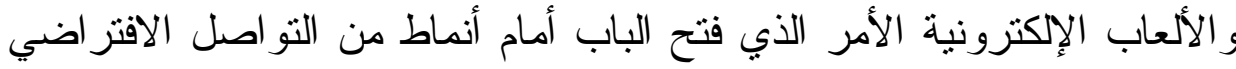

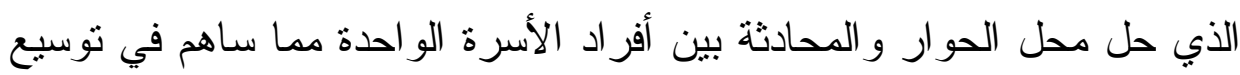
الهوة وتكريس الصراع بين جيلي الآباء والأبناء، وقد أفرزت هذه التحولات

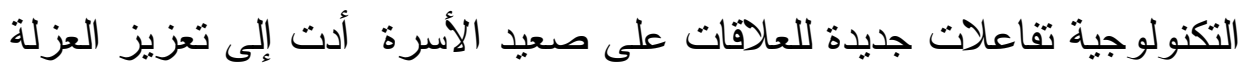

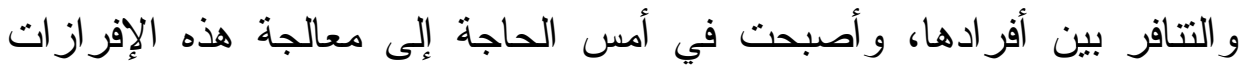

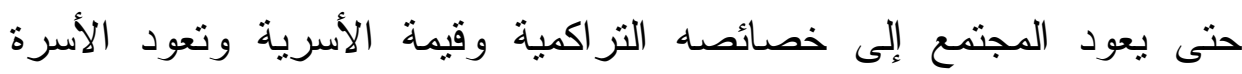
لدور ها الرئيسي في التربية و التوجيه و الوصول إلى أنسب السبل للاستفادة من التهن الجو انب الإيجابية لوسائل التو اصل الحديثة. تأثير المواقع الاجتماعية: فرضت وسائل التو اصل الاجتماعي نفسها وبقوة داخل المجتمعات في السنوات الأخيرة ويرجع ذلك لعدد من الأسباب نجملها في الآتي:1- إن شبكات التو اصل الاجتماعي شبكات عالمية. 2- أنها متاحة للجميع وبالمجان تقريباً. 


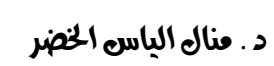

3- أنها صمدت أساساً لتكون سهلة الاستخدام وبدون تعقيدات. 4- أنها عملت على تكوين مجتمعات افتر اضية جديدة.

5- أنها جمعت لأول مرة بين النص المكتوب و المقطع المرئي.

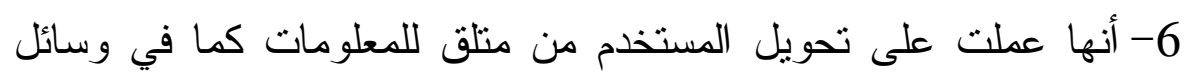
الإعلام التقليدية إلى منتج للمعلومات ومشارك فئه الكيا. 7- إن الكثير من الثباب يستخدم شبكات التواصل الاجتماعي للاردشة

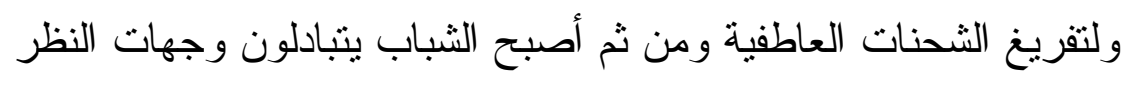
الثقافية و الاجتماعية و السياسية عبر تلك الثبكات. 8- أنها مصدر جديد وجيد للمعلومات. 9- وفرت مساحات كبيرة للشباب للتعبير عن وجهات نظرهم بعيداً عن للمدئ مقص الرقيب.

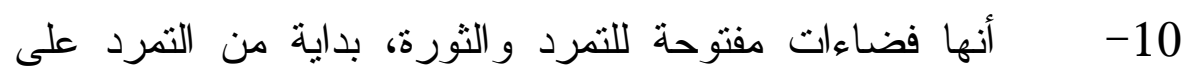

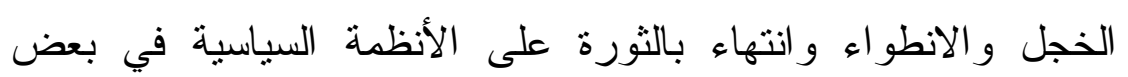
الأحيان.

11 - أنه يمكن الاستفادة منها في العديد من الخدمات التعليمية

$$
\text { و التقافية و الإخبارية }
$$

12 - يمكن اعتبارها سجل أرشيف موثق عبر شبكة الإنترنت يمكن

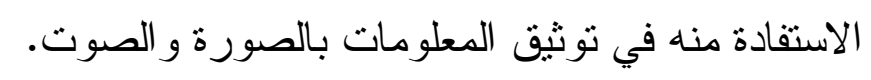

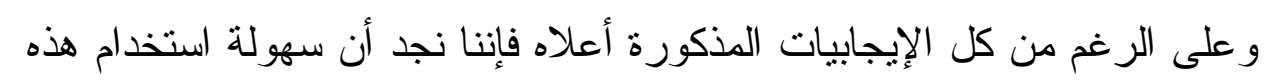

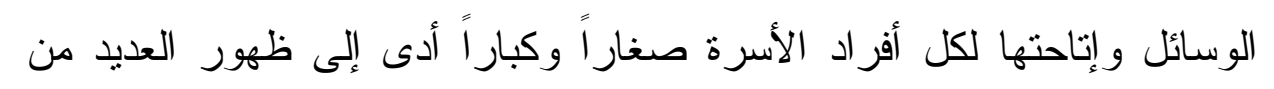

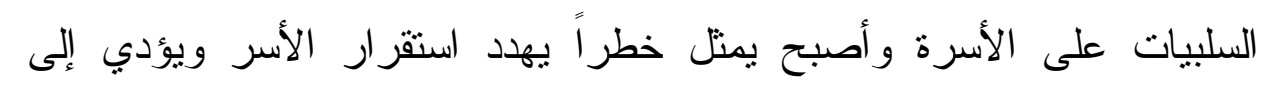
تفكها وتهام بنائها وتتمثل السلبيات في الآتي: 


\section{تأثير وسائله التواصله الاجتماعي على الأسرة الطسلمة}

1- التنشئة الاجتماعية:

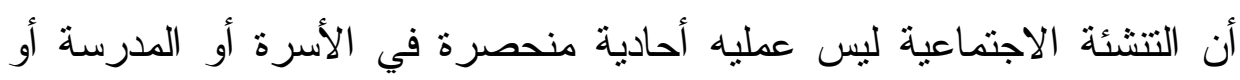

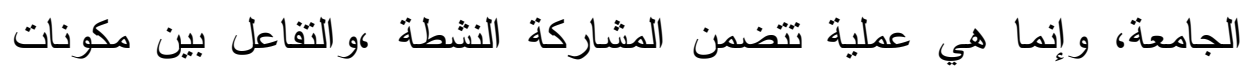

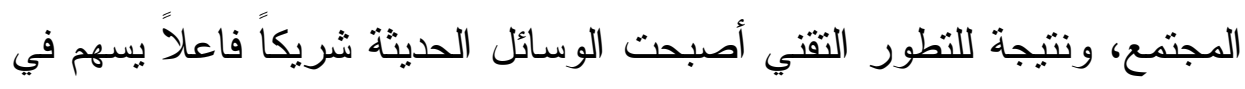
عملية التنشئة الاجتماعية، و التربوية، بجانب الأسرة وترتب على ذلك اكتساب

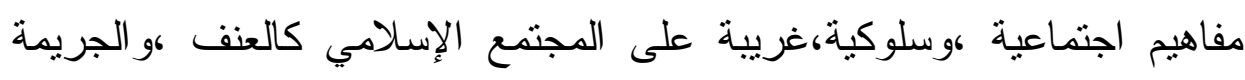

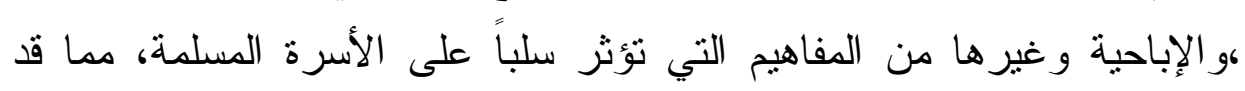

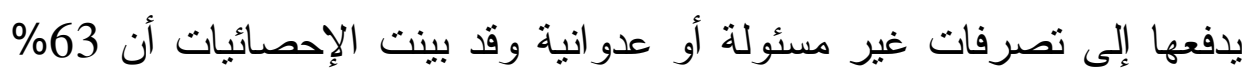

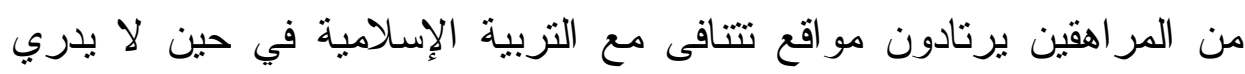

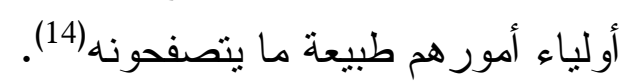

2- تفتيت النسيج الأسري:

أدت وسائل التواصل الاجتماعي إلى تفتيت النسيج الأسري وقلة النتواصل الاجتماعي بين أفراد الأسرة وذللك من خلال قضاء الكثير من وقت الألى الآباء

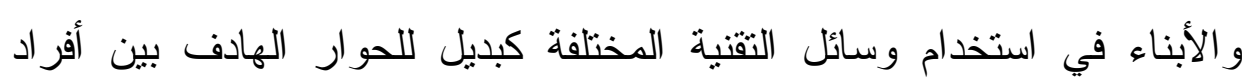
الأسرة و التو اصل، و التر احم، و التعاون مع بقية أفر اد الأسرة و المجتمع. 3-ظهور المشكلات والخلافات الزوجية:

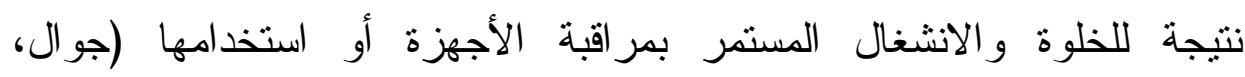

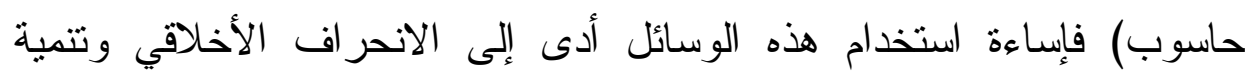

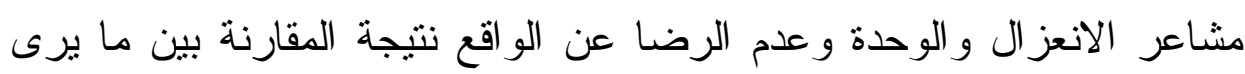

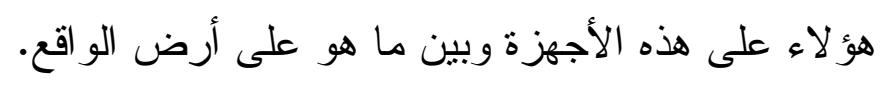

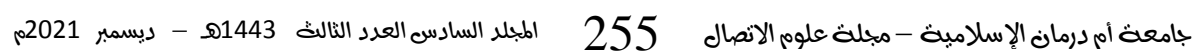


فجلوس الأبناء لساعات طويلة برفقة هذه الأجهزة أدى إلى إدمانهم لها و اكتسابهر

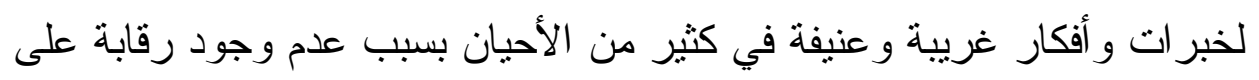
ما يشاهدون أو ما يقومون به من أعمال أو تتظيم أوقاتهم.

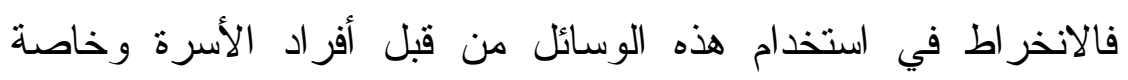

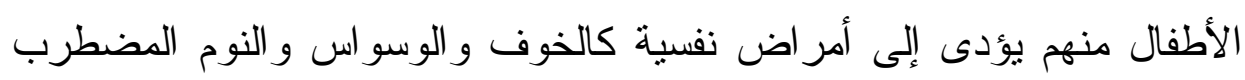

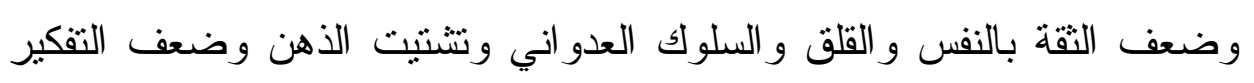
و الانطو اء، و الخلط بين الواقع و الخيال و عدم تعاون الأطفال مع الغير و الثنك في ولني سلوك الآخرين وضعف الثخصية و الصعوبة في محاورة الآخرين.

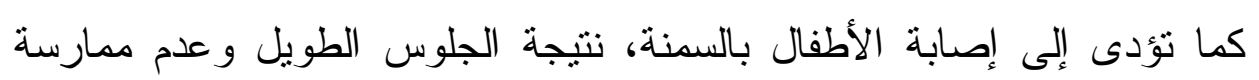

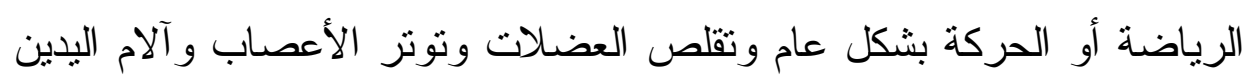

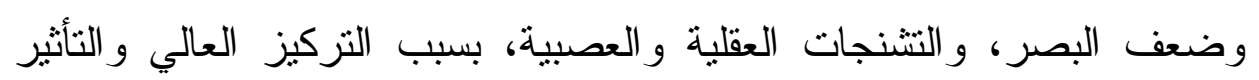
السلبي على المستوى الدر اسي و التحصيل الأكاديمي. 5- التأثير الاقتصادي:

أدى استخدام وسائل التواصل الاجتماعية إلى آثار اقتصادية سالبة على الأسرة

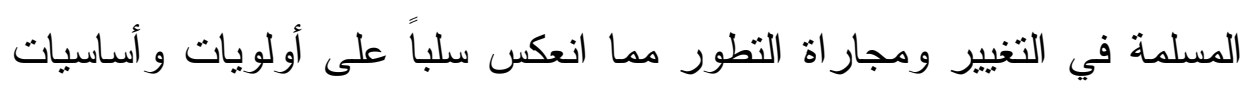

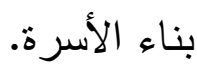

6- زيادة الاهتمام بالثقافة الصورية أكثر من الثقافة المكتوبة:

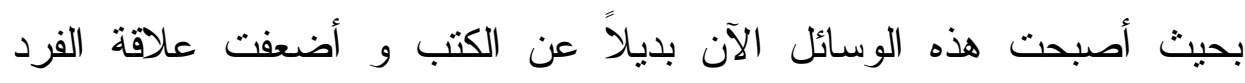

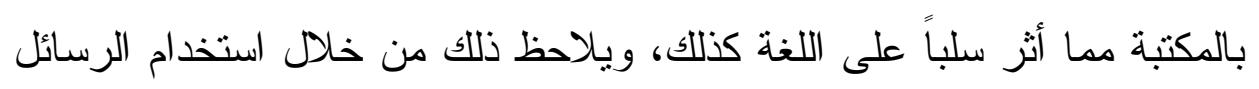

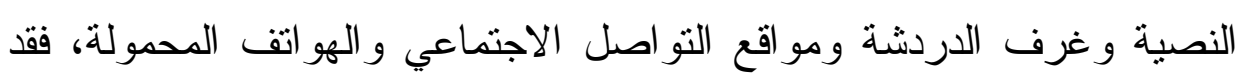
أصبحت اللغة تستخدم باختصار ات ورموز جديدة. 


\section{تأثير وسائل التواصله الاجتماعي على الأسرةً الطسلمة 7-طمس الهوية الثقافية للمجتمعات الإسلامية:}

وذلك من خلال زيادة مساحة بث البرامج و الرسائل المستوردة مما أدى إلى الى الئل تكريس القيم السلبية وذلك لأن البرامج والرسائل التي تصدر للأدول النامية

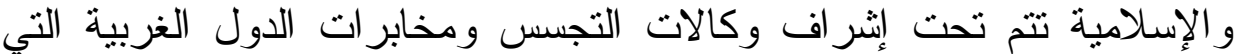
تسعى إلى تثكيل الر أب العام. 8- - العلاقات الاجتماعية الخاطئة:

إن الاستخدام الخاطئ لوسائل التقنية خاصة الهاتق السيار ومواقع التو اصل التصل الاجتماعي وغرف الدردشة أدى إلى تكوين شكل جديد من العلاقات بين الجنسين و التي تخالف مبادئ الثر ع الإسلامي مما يؤثر سلباً على حياة الأسرة

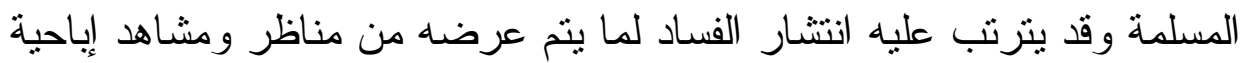
تسعى إلى محو الهوية و العمل على الانحلال و التنكك الأسري (15).

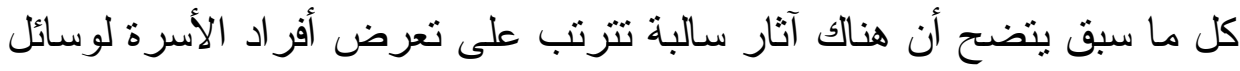

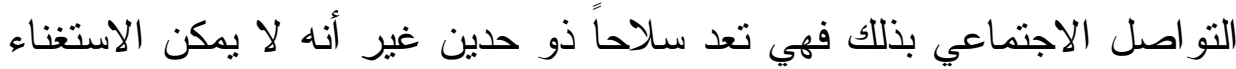

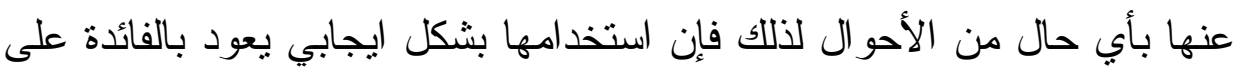

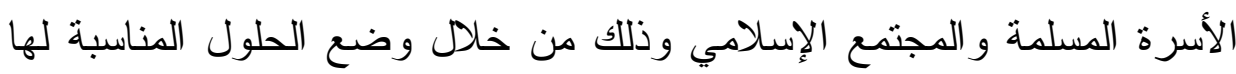
وتعريف الأسرة المسلمة بكيفية التعامل معها، وذلك بالآتي:

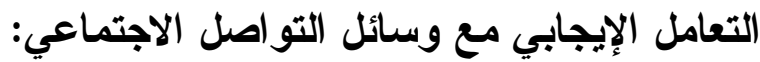
يبدأ التعامل الايجابي مع هذه الوسائل بالآتي: • بإدراك استحالة عدم تعرض أفراد الأسرة لهذه الوسائل بصورها:

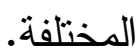
• الاعتراف بوجود جوانب سلبية وايجابية لتعرض أفراد الأسرة لهذه

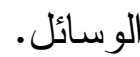

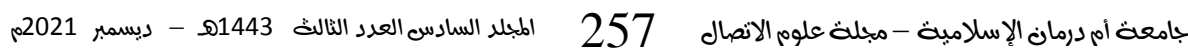


د. منال الباسه الخضر

الاهتمام بالأخذ بأساليب متعددة ومتكاملة لمواجهة الثأثير السلبي لهذه

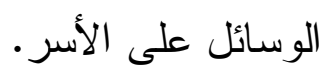

الاهتمام بتوفير الدعم العاطفي للأطفال و الثباب كوظيفة مكملة لمهام التشئة الاجتماعية. وجود قدر من الاتفاق والأرضية المشتركة بين الو الدين في النظرة إلى الى الئه وسائل التو اصل و أساليب التعامل معها. بالإضافة إلى كل ذلك هناك قضيتان رئيستان يجب أن تهتم بهما الأسرة

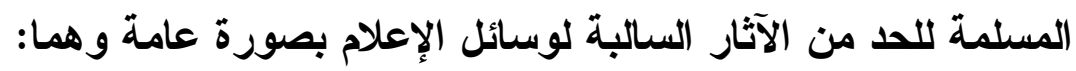
القضية الأولى: التزبية الإعلامية:

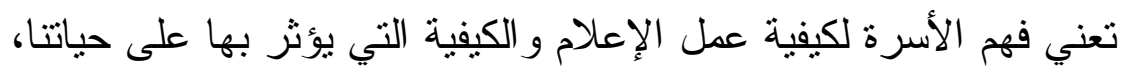
وكيفية استخدام وسائل الإعلام بصورة حكيمة وإيجابية وفي هذه النقطة يحتاج الوالدان إلى وضع بعض القيود، و التدخل فيما يتعرض لله الأبناء من وسائل ولئل

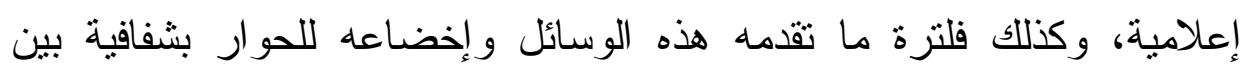

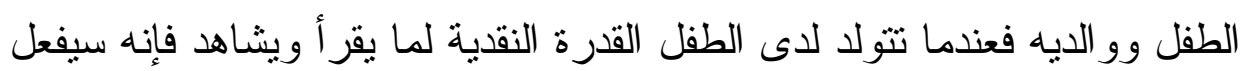

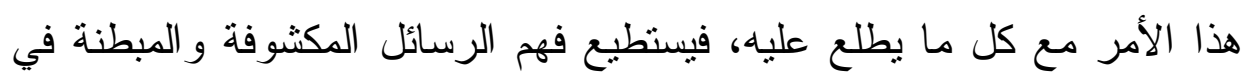
كل وسائل الإعلام كما يستطيع الو الدان مساعدة أطفالهم على الاستخدام الأمتل

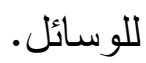

\section{القضية الثانية: المسؤولية الاتصالية:}

تعني تأثير الأسرة في أهداف وسياسة الاتصال من خلاد تبني مواقفاله و أفعال تجاه ما تعرضه وسائل الإعلام، وذللك بوضع خطة إعلامية تحدد أوقات

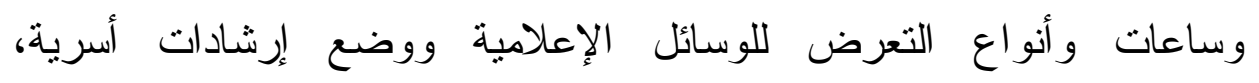

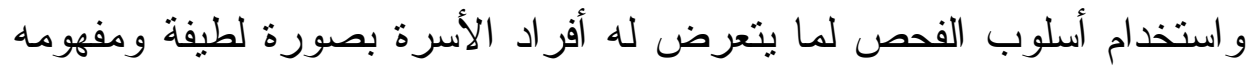




\section{تأثير وسائل التواصل الاجنتماعي على الأسرة الطسلمة}

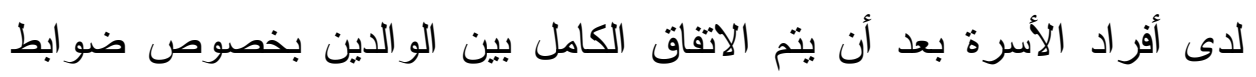

$$
\text { الألتعامل مع وسائل التو اصل. الميداتية }
$$

اعتمدت الدراسة الميدانية على جمع معلومات وآراء المبحوثين فيما يتعلق بتعرض أفر اد الأسرة لوسائل التواصل الاجتماعي وما ينرتب عليه، وتن عرض الاستبانة على عدد من المحكمين المختصين في مجال الإعلام وبعد ذلك الك الك

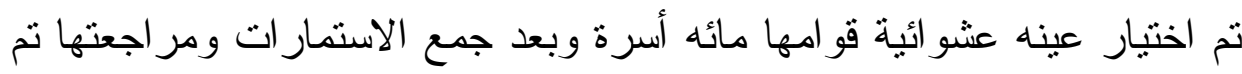

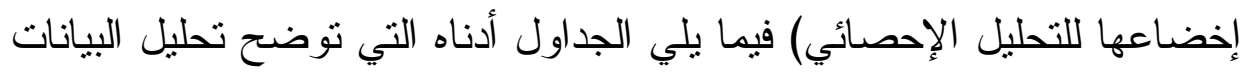

\begin{tabular}{|c|c|c|}
\hline النسبة & التكرار & الفئة \\
\hline 30 & 30 & ذكر \\
\hline 70 & 70 & أنثي \\
\hline 100.0 & 100 & الججموع \\
\hline
\end{tabular}

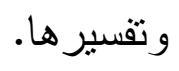

جدول رقم (1) يوضح النوع

يتضح من الجدول رقم (1) أن نسبة 30\% من أفراد العينة المبحوثين من الذكور، ونسبة 70\% من أفراد العينة المبحوثة من الإناث، يلاحظ في هذا من فئه

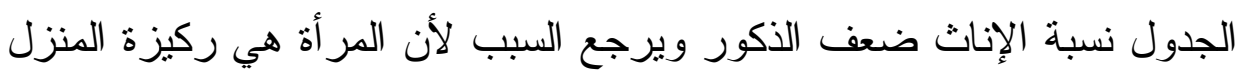

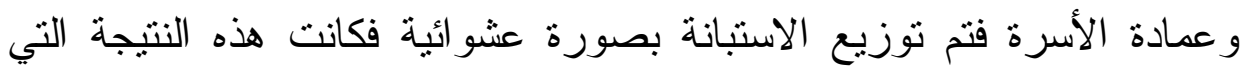
توضح أهية دور المرأة في المجتمع. جدول رقم (2) يوضح العمر

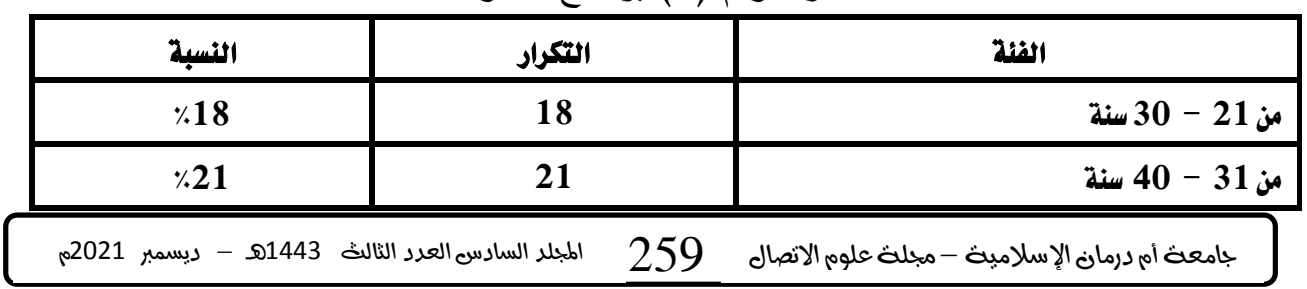




\begin{tabular}{|c|c|c|}
\hline & د. منال الباسه الخضر & \multirow[b]{2}{*}{ مز 41 - 50 سنة } \\
\hline$\% 27$ & 37 & \\
\hline$\% 10$ & 10 & هن 51 - 60 سنة \\
\hline$\% 14$ & 14 & 61 سنة فأكثر \\
\hline$\% \mathbf{1 0 0 . 0}$ & 100 & المجموع \\
\hline
\end{tabular}

من الجدول رقم (2) يتضح أن نسبة 18\% من أفراد العينة المبحوثة نتراوح أعمار هم من 25-30 سنة، ونسبة 21\% من المبحوثين تتراوح أعمار هم من

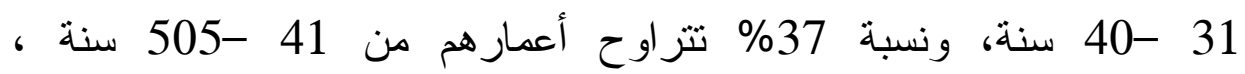
ونسبة10\% تتراوح أعمار هم من 51- 60 سنة ، ونسبة 14\% أعمار هم من 61 سنة فأكثر. ولا شك أن هذه النسبة العالية من المبحوثين من من الآباء

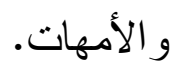

جدول رقم (3) يوضتح عدد أفر اد الأسرة:

\begin{tabular}{|c|c|c|}
\hline النسبة & التكرار & الفئة \\
\hline$\% 15$ & 15 & 3-2 \\
\hline$\% 64$ & 64 & $5-4$ \\
\hline$\% 21$ & 21 & 6 فنكثر \\
\hline$\% 100$ & 100 & المجموع \\
\hline
\end{tabular}

الجدول أعلاه يوضح عدد أفر اد أسر المبحوثين وبه إثـارة و اضحة إلى أن غالبية العينة من الأسر متوسطة العدد إذ بلغت الأسر التي تتكون من أربعة إلى إلى خمسة أثخاص نسبة 64\% من العينة. جدول رقم (4) يوضح عدد أجهزة الهو اتف الذكية بمنازل المبحوثين

\begin{tabular}{|c|c|c|}
\hline النسبة & التكرار & الفئة \\
\hline$\% 9$ & 9 & 3-2 \\
\hline$\% 71$ & 71 & $5-4$ \\
\hline$\% 20$ & 20 & 6 فنكثر \\
\hline$\% 100$ & 100 & المجموع \\
\hline
\end{tabular}




\section{تأئير وسائز التواصله الاجتماعي على الأسرةً الطسلمة}

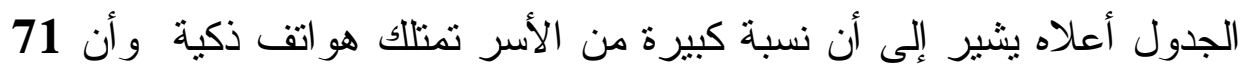
\% من هذه الأسر تمثلك ما بين (4) إلى (5) أجهزة وهو مؤشر إلى أن الأجهزة الأكية أصبحت متاحة ومهمة لكل أفر اد الأسرة. جدول رقم (6) هل يستخدم أفر اد الأسرة وسائل التو اصل الاجتماعي؟ ومة الاسرة

\begin{tabular}{|c|c|c|}
\hline النسبة & التكرار & الفئة \\
\hline$\% 87$ & 87 & مe \\
\hline$\% 13$ & 13 & 2 \\
\hline$\% 100.0$ & 100 & للجموع \\
\hline
\end{tabular}

من الجدول رقم (6) يوضح أن نسبة.87\% من المبحوثين يستخدمون وسائل

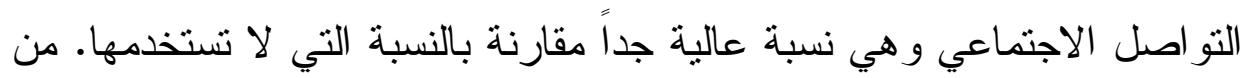

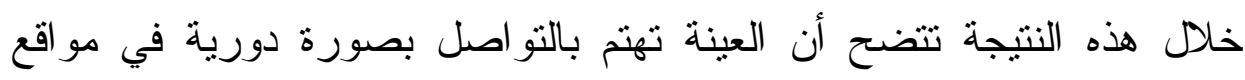

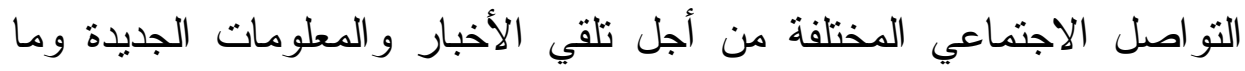
يدور في المحيط الاجتماعي.

جدول رقم (7) يوضح إذ كانت الإجابة بنعم هل يقوم الآباء بمر اقبة أجهزة الصغار؟

\begin{tabular}{|c|c|c|}
\hline النسبة & التكرار & الفثلة \\
\hline \%74 & 74 & نعم \\
\hline$\% 26$ & 26 & y \\
\hline$\% 100.0$ & 100 & الججموع \\
\hline
\end{tabular}

من الجدول رقم (7) يتضح أن نسبة 74\% من المبحوثين يهتمون بمتابعة ما

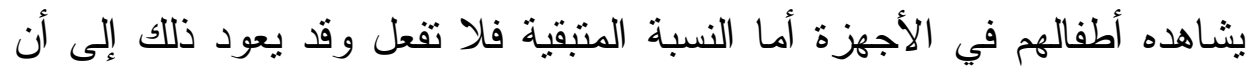

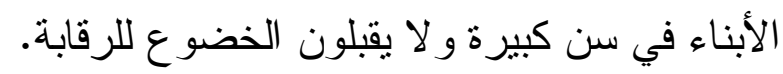

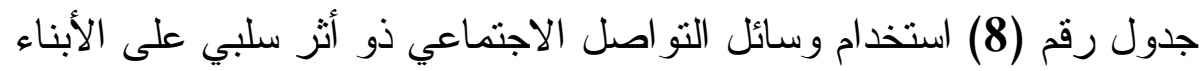

\begin{tabular}{|c|c|c|}
\hline أوافق & التقار \\
\hline
\end{tabular}

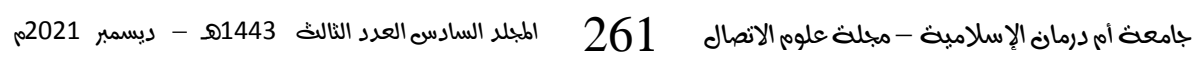




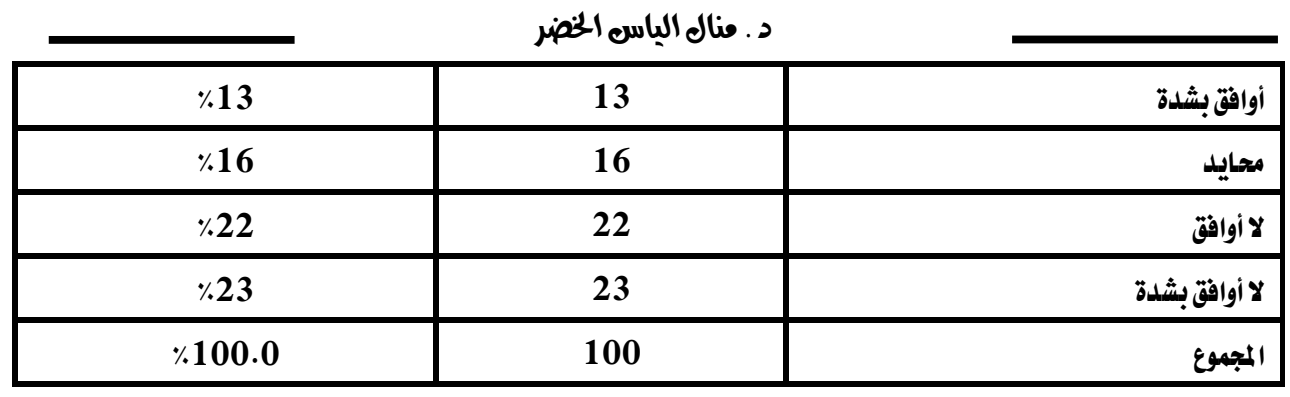

من الجدول رقم (8) يتضح أن هناك تباين في آراء المبحوثين حول الأثر السالب لمو اقع النو اصل الاجتماعي. جدول رقم (9) استخدام وسائل التو اصل الاجتماعي قلل من الحوار

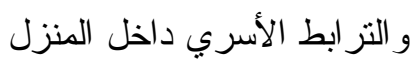

\begin{tabular}{|c|c|c|}
\hline النسبة & التكرار & الفئة \\
\hline$\% 15$ & 15 & أوافق \\
\hline$\% 54$ & 54 & أوافق بشدة \\
\hline$\% 5$ & 5 & محايد \\
\hline$\% 16$ & 16 & لاأوافق \\
\hline$\% 10$ & 10 & لا أوافق بشدة \\
\hline$\% 100$ & 100 & المجموع \\
\hline
\end{tabular}

الجدول أعلاه يتضح أن النسبة الأعلى من المبحوثين نرى أن استخدام وسائل

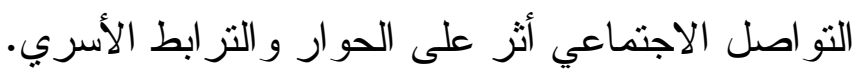
وفي تحليل الأسئلة المفتوحة خلصنا إلى العديد من الآراء تتمنل في ضرورة

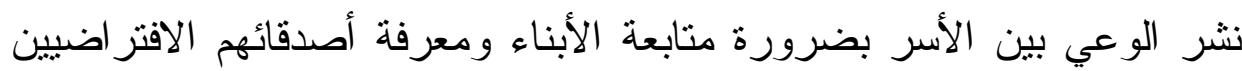

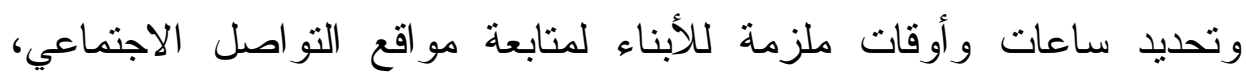

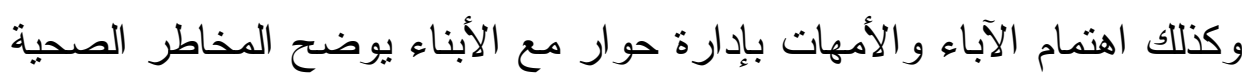
و النفسية الناجمة عن الاستخدام غير المرشد لهذه الوسائل. نتائج الاراسة: خلصت هذه الدراسة بثقيها النظري و النطبيقي لعدد من النتائج أهمها: 1- للأسرة دور مهم في غرس الأخلاق الفاضلة في الفرد و المجتمع. 


\section{تأثير وسائله التواصله الاجتماعي على الأسرة الطسلمة}

2- التزبية السليمة تبدأ في المر احل الأولى للطفولة.

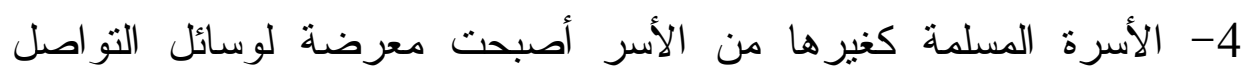
الاجتماعي بسهولة ويسر وتتلقي العديد من الرسائل الايجابية و السلبية.

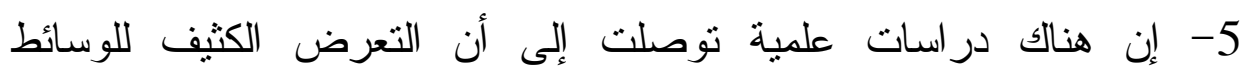
الاككترونية قد يكون له أثز سالب علي التتشئة الاجتماعية و النسيج الأسري.

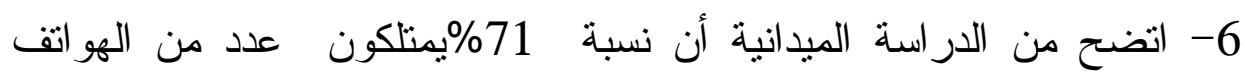
الذكية

7- 87 من المبحوثين يستخدمون وسائل التو اصل الاجتماعي . 8.

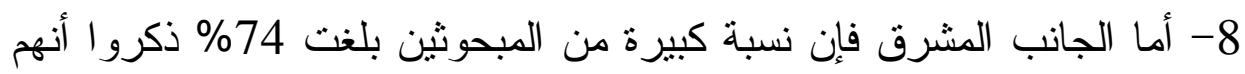

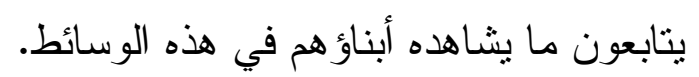
9- نباينت آراء المبحوثين فيما إذا كان هناك فئك تأثير سلبي نتيجة التعرض لهذه الوسائط إلا أن النسبة الأعلى منهم اتفقت مع هذا الر الر أي.

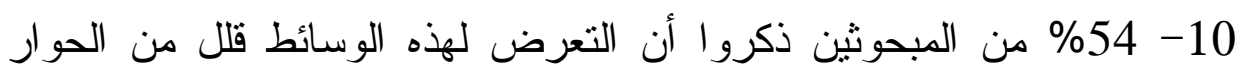
و التزر ابط الأسري.

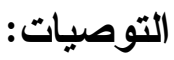

1- تضافر الجهود بين الأسرة ومؤسسات المجتمع الأخرى مثل المدرسة

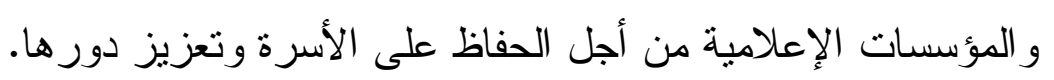

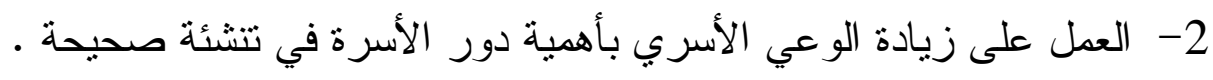

$$
\text { 3- إدر اج الثربية الإعلامية في المناهج الدراسية الألية. }
$$

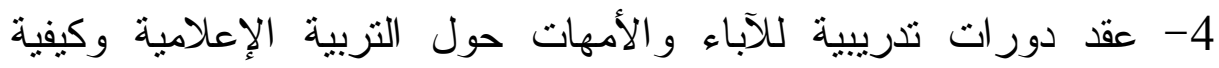

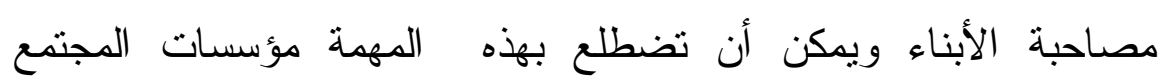

$$
\text { المدني. }
$$

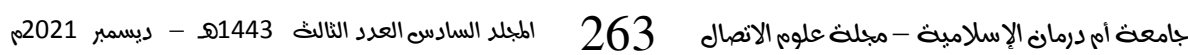


5- إبر ام اتفاقيات دولية من شأنها تقوية القيم الدينية و المجتمعية و العمل على السيطرة على شبكات الإنترنيت خاصة التي تخاطب الثباب بحيث تطر ح بر امج تعليمية بدلاً من البرامج التي تذعو للتفسخ و الانحلال و الإجرام . 6- عقد المؤتمر ات و الورش و الدور ات و إجر اء الدر اسات و البحوث التي تهنم بقضايا الأسرة. الهوامش:

1- عاتكة محمد طه خالد اتجاهات الر أي العام النوعي نحو استخدام وسائل التو اصل الاجتماعي رسالة ماجستير غير منشوره بكلية الإعلام جامعة ام درمان الإسلامية 2016م.

2- ماجد بن عبد الله العصيمي ، التحديات الاجتماعية للانترنت و إثرها علي

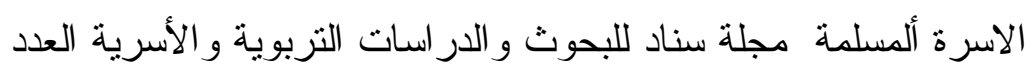
الاول بتاريخ يناير 2020 م مجلة نصف سنوية محكمه يصدر ها المركز

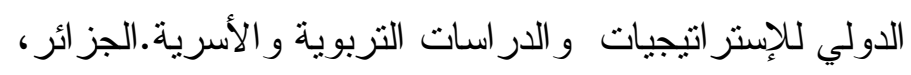

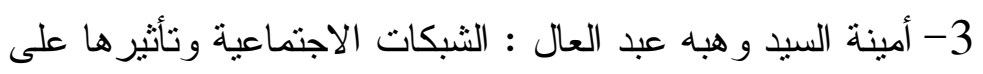
الأخصائيو المكتبة در اسة منشورة ، جامعة حلو انيه الني القاهرة

4- إحصائيات وسائل التو اصل الاجتماعي 2018م ، كل ما تحتاج لمعرفته ، مركز النبأ الوثائقي annabaa010@gmail.com ، تاريخ زيارة الموقع ملئي

$$
\text { 2019/1/30 }
$$

5- إحصائيات وسائل التو اصل الاجتماعي 2018م ، كل ما تحتاج لمعرفته ،

$$
\text { 6- مصدر سابق • المرجع السابق • }
$$

WWW.linkedin .com.6octoper -7

8- إحصائيات وسائل التو اصل الاجتماعي 2018م ، كل ما تحتاج لمعرفته ،

$$
\text { • مصدر سابق }
$$




\section{تأئير وسائل التواصله الاجنماعي على الأسرةً اطسلمة}

www.youtube.com.6octoper -9

10-ز اهر رامى ، استخدام مو اقع التواصل الاجتماعي في العالم العربي ، عمان

$$
\text { 2013 }
$$

$$
\text { 121- لسان العرب ، بن منظور ، القورة القصص الآية } 29
$$

13- هناء السيد محمد علي ، عو اطف محمود عيسي ، الإعلام و الأسرة الريفية

$$
\text { دار العرب للنشر و التوزيع }
$$

$$
\text { 14-نركي عبد العزيز السديري ، توظيف شبكات التو اصل الاجتماعي في }
$$

التوعية ضد خطر الثائعات دراسة ماجستير غير منشورة (جامعة نايف

$$
\text { العربية للعلوم الأمنية ) الرياض 2014م .صلواله }
$$

15-سبدة محمود محمد ، الغزو الثقافي و الفكري الموجه للمر أة والأسرة و الطفل

و الحياة الاجتماعية ، مؤتمر الإتحاد النسائي الإسلامي العالمي ، (الخرطوم :

$$
\text { (السودان ، 2011م) }
$$

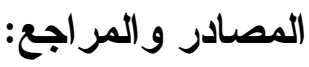

1. إحصائيات وسائل التو اصل الاجتماعي 2018م ، كل ما تحتاج لمعرفته

، مركز النبأ الوثائقي annabaa010@gmail.com ، تاريخ زيــارة

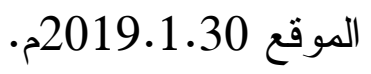

2. أمينة السيد وهبه عبد العال : الثــبكات الاجتماعيــة وتأثنير هـــا علــى الأخصائي و المكتبة در اسة منشورة ، جامعة حلو اني القاهرة

3. تزكي عبدالعزيز السديري ، توظيف شبكات التو اصل الاجتماعي فـي

التوعية ضد خطر الثائعات در اسة ماجستير غير منشورة (جامعة نايف

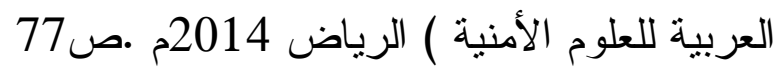




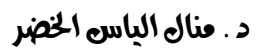

4. زاهر رامى ، استخدام مواقع التو اصل الاجنماعي في العالم العربـي ،

$$
\text { عمان 2013م }
$$

5. سورة القصص الآية 29

6. سيدة محمود محمد ، الغزو الثقافي و الفكري الموجه للمــر أة و الأســرة

و الطفل و الحياة الاجتماعية ، مؤتمر الإتحاد النسائي الإسلامي العالمي ،

$$
\text { (الخرطوم : السودان ، 2011م) }
$$

7. عاتكة محمد طه خالد، اتجاهات الرأي العام النوعي نحو استخدام وسائل التو اصل الاجتماعي رسالة ماجستير غير منشوره بكلية الاعلام جامعة

$$
\text { ام درمان الاسلامية . الاعلمية }
$$

8. فاطمة عيد العدوان،أسماء عبد الحسين النجار :الإرشادالأسري،دار

$$
\text { المسيرة للنشر و التوزيع عمان } 2016
$$

$$
\text { 9. لسان العرب ، بن منظور ، .... }
$$

10. ماجد بن عبد الله العصيمي، التحديات الاجتماعية للانتزنت و إثزرها علي الاسرة المسلمة، ملة سناد للبحوث و الدر اسات التربويه و الأسرية العدد الاول بتاريخ يناير 2020 م وهي مجلة نصف سنويه محكمه يصدر ها المركز الدولي للإستز اتيجيات و الدر اسات التزبوية

$$
\text { و الاسرية. }
$$

11. هناء السيد محمد علي ، عو اطف محمود عيسي ، الإعــلام و الأســرة

$$
\text { الريفية دار العرب للنشر و التوزيع · }
$$

12. التعليم الاكتروني و البرمجيات الاجتماعية.مجلة المعرفة العدد 182

$$
\text { مايو 2010م. }
$$

13. WWW.linkedin .com.6octoper

14. www.youtube.com.6octoper 